\title{
Estimating urban PM10 and PM2.5 concentrations, based on synergistic MERIS/AATSR aerosol observations, land cover and morphology data
}

\author{
Anton Beloconi ${ }^{\mathrm{a}, *}$, Yiannis Kamarianakis ${ }^{\mathrm{b}}$, Nektarios Chrysoulakis $^{\mathrm{a}}$ \\ ${ }^{a}$ Foundation for Research and Technology - Hellas, Institute of Applied and Computational \\ Mathematics, N. Plastira 100, Vassilika Vouton, 70013 Heraklion, Greece \\ ${ }^{b}$ School of Mathematical \& Statistical Sciences, Arizona State University, Tempe, AZ \\ 85287, USA
}

\begin{abstract}
This study evaluates alternative spatio-temporal approaches for quantitative estimation of daily mean Particulate Matter $(P M)$ concentrations. Both fine (PM2.5) and coarse (PM10) concentrations were estimated over the area of London (UK) for the 2002-2012 time period, using Aerosol Optical Thickness (AOT) derived from MERIS (Medium Resolution Imaging Spectrometer) / AATSR (Advanced Along-Track Scanning Radiometer) synergistic observations at $1 \mathrm{~km} \times 1 \mathrm{~km}$ resolution. Relative humidity, temperature and the K-Index obtained from MODIS (Moderate Resolution Imaging Spectroradiometer) sensor were used as additional predictors. High-resolution $(100 \mathrm{~m} \times 100 \mathrm{~m})$ local urban land cover and morphology datasets were incorporated in the analysis in order to capture the effects of local scale emissions and sequestration. Spatial (2-D) and spatio-temporal (3-D) kriging were applied to in situ urban $P M$ measurements to investigate their association with satellite-derived $A O T$ while accounting for differences in spatial support. Linear mixed-effects models with day-specific and site-specific random intercepts and slopes were estimated to associate satellite-derived products with kriged $P M$ concentration and their
\end{abstract}

\footnotetext{
* Corresponding author. Tel: +302810391762

Email addresses: beloconi@iacm.forth.gr (Anton Beloconi), ikamaria@asu.edu (Yiannis Kamarianakis), zedd2@iacm.forth.gr (Nektarios Chrysoulakis)

${ }^{1}$ This article is dedicated to the memory of V.K. Klonias
}

Preprint submitted to Remote Sensing of Environment

August 28, 2015

(C) 2015. This manuscript version is made available under the Elsevier user license http://www.elsevier.com/open-access/userlicense/1.0/ 
predictive performance was evaluated.

Keywords: Particulate Matter, Aerosol Optical Thickness, MERIS/AATSR synergy, Block Kriging, Change Of Support Problem, Mixed-Effects Models

\section{Introduction}

Particulate Matter $(P M)$ concentration of both fine (PM2.5) and coarse $(P M 10)$ particles is used as an air quality indicator in urban areas. Numerous studies, analysing the impacts of $P M$ on human health, have found associa5 tions of $P M$ with increased morbidity and mortality. Specifically, high $P M$ loads in urban areas produced by local sources like transportation and industry (Katsouyanni et al. 2001), have been correlated with increased respiratory problems (Dimitrova et al., 2012), cardiovascular diseases (Franklin et al., 2006) and decreased birth weights and lengths (Ballester et al. 2010).

Monitoring of $P M$ concentrations is primarily based on ground measurements. Despite the fact that dense station networks exist, in large cities like London, in situ measurements do not provide detailed information on the spatial distribution of $P M$ at local scale. The temporal coverage of in situ $P M$ measurements, which depends on the instrument operation period and functionality, is also highly variable. These reasons have prompted an ongoing effort for $P M$ estimation using satellite observations. $P M$ spatio-temporal distribution estimations derived by combined use of satellite observations, in situ measurements and numerical modelling was recently performed in five European cities, London included, in the framework of the FP7 project BRIDGE (Chrysoulakis 20 et al., 2014 ; Borrego et al., 2011).

Aerosol Optical Thickness $(A O T)$ is the most widely applicable satellitederived product for the assessment of $P M$ concentrations. AOT represents the integrated radiation scattering and absorption by aerosols in an atmospheric column from the surface to the top of the atmosphere; it is proportional to the number of airborne particles and, among other factors, depends on their mass concentration and size distribution. A variety of methods have been developed 
for the estimation of $A O T$ using spaceborne observations (e.g. Kokhanovsky, 2013), with the dark target approximation being the most widely used, as in the MODIS (Moderate Resolution Imaging Spectroradiometer) AOT products 30 at $10 \mathrm{~km} \times 10 \mathrm{~km}$ (Levy et al., 2013) and $3 \mathrm{~km} \times 3 \mathrm{~km}$ (Remer et al., 2013) spatial resolution. Multi-angle algorithms have also been recently developed, such as the MERIS (Medium Resolution Imaging Spectrometer) / AATSR (Advanced Along-Track Scanning Radiometer) synergy algorithm (North et al. 2009) and the MAIAC (Multi-Angle Implementation of Atmospheric Correc35 tion) algorithm (Lyapustin et al., 2011). These algorithms allow significant improvement in the $A O T$ spatial resolution, which, at $1 \mathrm{~km} \times 1 \mathrm{~km}$ renders the product suitable for intra-urban $P M$ studies.

Various techniques have been adopted to associate remotely sensed AOT with surface-measured $P M$. These include simple linear regression models 40 petween $A O T$ and $P M$ (Chu et al. 2003 ; Schaap et al., 2009 ; Wang and Christopher, 2003), multiple linear regression with additional covariates such as temperature, relative humidity, wind speed, boundary layer height (Gupta and Christopher, 2009a; Benas et al. 2013b), chemical transport models (van Donkelaar et al., 2006; van de Kassteele et al., 2006) integrating satellite radi45 ance (Drury et al., 2010; Wang et al., 2010), Generalized Linear Models (GLM) Liu et.al, 2005, 2007), Artificial Neural Networks (ANN) (Gupta and Christopher, 2009b; Wu et al., 2012), Generalized Additive Mixed (GAM) models (Liu et.al, 2009 ; Lee et al., 2012), Alternating Conditional Expectation (ACE) models (Benas et al. 2013b), Geographically Weighted Regression (GWR) (Song et 50 al. 2014) and semi-empirical models (Lin et al., 2015).

Application of mixed-effects models with day-specific random intercepts and slopes (Lee et al. 2011) revealed that daily calibrations of satellite AOT data using ground $P M$ measurements from a spatial monitoring network, provide substantially improved predictive power relative to static models. Furthermore, ${ }_{55}$ covariates such as Percent of Open Spaces, Elevation, Major Roads, Population Density and Meteorological variables, explained part of the spatial variability of $P M$ concentrations within a day (Kloog et al., 2011; Nordio et al., 2013). Un- 
fortunately such spatial predictors are in general difficult to obtain, or even unavailable for many areas of interest. Moreover, a limitation of previous studies is the coarse spatial resolution $(10 \mathrm{~km} \times 10 \mathrm{~km}$ and $3 \mathrm{~km} \times 3 \mathrm{~km})$ of $A O T$ retrieved from MODIS sensor. In this work, the high-resolution $1 \mathrm{~km} \times 1 \mathrm{~km}$ AOT distributions derived by employing the MERIS/AATSR synergy algorithm developed by North et al. (2009) and validated by Benas et al. (2013a), were used. The Sky View Factor - SVF (Lindberg and Grimmond, 2010), accounting for the urban morphology and a post-classification of the Urban Atlas Land-Use/Cover - LUC (Urban Atlas, 2014) product are employed, to the best of our knowledge for the first time, to capture the spatial variability of $P M$ concentrations within the study domain. These remotely-sensed spatial predictors are much easier to obtain in comparison with data used in previous works.

The present study uses data from multiple sources, measured at different spatial units. Combining such dissimilar data creates statistical challenges (Young et al. 2009) and leads to what is known as the change of support problem, which is concerned with valid inference regarding a spatial variable of one support ( $n$-dimensional physical volume of the measured variable, including its geometric size, shape and spatial orientation) from data of different supports. Most research works that associate satellite-derived products with in situ $P M$ concentrations do not focus on this issue: typically, areal data are used as point-referenced data by assigning the value of each pixel to the corresponding centroid. Unfortunately such practices may lead to aggregation bias as emphasized in the geostatistics literature (e.g. Armstrong, 1998, Gotway and Young 2002). To address this issue, before associating satellite-derived products with in situ measurements, the latter were transformed using block-kriging, in accordance with the methodology presented in Young et al. (2009). The common geographical unit for analysis was selected to be $1 \mathrm{~km} \times 1 \mathrm{~km}$, matching the 85 spatial resolution of the MERIS/AATSR derived AOT.

Benas et al. (2013b) applied kriging to homogenize in situ PM10 measurements with satellite data with regard to their spatial scale. Nonetheless, simple kriging fails to account for local emission sources, such as the presence of in- 
dustrial areas or highways between different monitoring stations, as well as for local sequestration actors (e.g. urban green infrastructure). This article investigates whether incorporation of categorical $L U C$ and $S V F$ static datasets could improve such limitations. The Urban Atlas $L U C$ was expected to capture emission sources, while the $S V F$, derived from a high spatial resolution Digital Surface Model (DSM), was used as a proxy of the urban form (structure of the three-dimensional urban surface) and was expected to explain the dispersion of particles in the urban canopy.

Last, but not least, among the main objectives of this work was to develop an operational tool capable to estimate high resolution PM10 and PM2.5 concentration maps on a daily level, based only on satellite-derived products: highresolution $1 \mathrm{~km} \times 1 \mathrm{~km}$ AOT calculated by implementing the MERIS/AATSR synergy algorithm, relative humidity, temperature, and the K-Index (which is used as a proxy of the vertical aerosol mixing) from MODIS sensor. To this end, mixed-effect models with a) day-specific and b) site-specific random effects were estimated. The former are analogous to the "Stage 1" models presented by Kloog et al. (2011) for estimation of PM2.5 and by Nordio et al. (2013) for estimation of PM10 particles, where the $10 \mathrm{~km} \times 10 \mathrm{~km}$ resolution $A O T$ from MODIS was used. The latter models are used for the first time, to investigate whether satellite-derived products can estimate $P M$ concentrations in areas where no daily in situ measurements are available.

\section{Study area and datasets}

Greater London roughly coincides with the built-up area of London, including parts of the Metropolitan Green Belt. According to Eurostat, London is the most populous city and metropolitan area of the European Union with a population density of 4,761 people per square kilometre. London air quality is continuously monitored at over 100 locations London Air Quality Monitoring Network, 2014), with particulate matter being measured at the majority of the stations (Fig. 1 a); these stations formed the basis upon which the particular 
study area was chosen. The UK Air Quality Standards Regulations sets standards (based on EU limit values) for a variety of pollutants considered harmful to human health and the environment. Despite reductions for the majority of pollutants in the last years, the levels of PM10 continue to exceed national air quality standards and objectives in some areas of London (Greater London Authority, 2014).

Hourly mean PM10 and PM2.5 concentrations were obtained through the openair open-source tool for the analysis of air pollution data Carslaw and Ropkins, 2012), developed by the Environmental Research Group at King's College London and supported by the University of Leeds. Hourly data were used to calculate average daily $P M$ concentrations. The study period was selected to be 2002-2012, in order to match with the available MERIS and AATSR observations. All data was converted to the Lambert Azimuthal Equal Area (ETRS89-LAEA5210) projection, recommended by the European Environment Agency (EEA, 2006) for storing raster data, statistical analysis and map display purposes.

The MERIS/AATSR synergy algorithm for aerosol retrieval (North et al. 2009), available in the BEAM software toolbox of the European Space Agency (Brockmann Consult, 2011), was used to derive the AOT distribution. To this end, a java-based code was implemented to automatically produce $A O T$ values for the whole 2002 - 2012 time period, as well as to adjust and reproject the results to our study area. An advantage of the synergy is that it provides $A O T$ values at a $1 \mathrm{~km} \times 1 \mathrm{~km}$ spatial resolution in comparison to the $10 \mathrm{~km} \times 10 \mathrm{~km}$ given by MODIS. Figure 1(b) illustrates an example of the synergy derived AOT product; a fixed $1 \mathrm{~km} \times 1 \mathrm{~km}$ grid was created to be a common geographical unit for all further analyses.

Another advantage of the MERIS/AATSR synergy is that aerosol data are 145 provided in case of high-surface reflectance, where MODIS AOT retrieval algorithm fails. This is due to the dual view geometry of the synergy algorithm: while in single-view methods the separation of the surface contribution to the sensor measurement is based on a priori assumptions (e.g. the dark target ap- 
proximation, Remer et al., 2005), use of multiple view-angle imagery allows an additional constraint to be placed, since the same area is viewed through different atmospheric path lengths. Hence, no a priori information of the surface spectrum is required, and aerosol properties can be retrieved over all surface types (North et al., 2009).

The main sources of error in the final AOT product are related to algorithm

155 more frequent within a year relative to MERIS/AATSR.

The European Urban Atlas $L U C$ is part of the local component of the GMES/Copernicus land monitoring services. Satellite imagery has been used to create reliable high-resolution maps of urban land in a cost-efficient manner. 175 It provides data related to transport, environment and land use for Large Urban Zones with more than 100,000 inhabitants as defined by the Urban Audit. Figure 2(a) illustrates the polygon-shaped $4 m \times 4 m$ resolution $L U C$ map for the Greater Area of London, which includes 20 distinct classes.

$S V F$ is the fraction of sky visible when viewed from the ground up. It is a 
dimensionless variable that ranges from 0 to 1 . A value of 1 denotes that the sky is completely visible, i.e. in a flat terrain; when a location has buildings or trees $S V F$ decreases proportionally. For the calculation of $S V F$ the Relief Visualization Toolbox Computation, version 1.0 (Zaks̆ek et al., 2011) was used to analyze a lidar-derived high spatial resolution DSM. The DSM was made available by the Greater London Authority in the framework of the BRIDGE Project (Chrysoulakis et al. 2013). The resulting raster map has a $4 \mathrm{~m} \times 4 \mathrm{~m}$ resolution (Fig. 2 b). $S V F$ is a remote sensing product; in our analyses it was adopted as an alternative to the more commonly used "Percent of Open Spaces" covariate (e.g. used in Kloog et al. 2012).

Atmospheric temperature and relative humidity profiles at 20 pressure levels $(1000 h P a-5 h P a)$, as well as surface pressure, were retrieved from the MODIS Level 2 Atmospheric Profile Product for the period examined (2002-2012). Surface Temperature $(S T M P)$ and Relative Humidity $(R H U M)$ were estimated using linear interpolation or extrapolation of atmospheric profiles and corresponding surface pressure data. The K-Index - KIND (George, 1960), an atmospheric static stability estimator, was used as an indicator of the corresponding aerosol vertical mixing height as in Benas et al. (2013b). The aforementioned data, available on a daily basis and at $5 \mathrm{~km} \times 5 \mathrm{~km}$ spatial resolution, were reprojected to the geographical system of the study and resampled to our $1 \mathrm{~km} \times 1 \mathrm{~km}$ grid using bilinear interpolation. Hence, it was assumed that the variability of these data is small within the $5 \mathrm{~km} \times 5 \mathrm{~km}$ grid; we acknowledge the limitation of this approach, particularly in the case of $R H U M$.

\section{Model Development Methodology}

To address the change of support problem all data was brought to the same spatial resolution, selected to be $1 \mathrm{~km} \times 1 \mathrm{~km}$, which is the resolution of the satellite-derived $A O T$. To this end, in situ $P M$ were interpolated using spatial - 2-D and spatio-temporal - 3-D kriging (discussed in Sect. 3.2). Thus, $100 m \times 100 m$ blocks were obtained and the resulting surface was up-scaled to 
a $1 \mathrm{~km} \times 1 \mathrm{~km}$ grid, by averaging per each $10 \times 10$ cell. To exploit the high

spatial resolution of $L U C$ and $S V F$, interpolation was applied to the residuals of the multiple linear regression model, which used these variables as predictors. Finally, the predictive capability of linear mixed-effects models (Sect. 3.3 and 3.4 with day-specific and site-specific random effects was evaluated. Figure 3 illustrates a graphical representation of the adopted procedure. In what follows

the estimation procedure is presented in full detail for $P M 10$; the same steps were applied for the estimation of $P M 2.5$.

\subsection{LUC \& SVF - PM Relationship}

Average daily $P M$ concentrations are expected to vary for different $L U C$ classes. To better understand the urban surface characteristics that surround $P M$ stations, a buffer zone of $100 m \times 100 m$ around each station point was created. Then, the $L U C$ map was clipped with these buffer zones and the dominant $L U C$ category within each buffer zone was assigned to the respective $P M$ site (Fig. 4 a). The resulting land cover classes $\left(L U C_{k}, k=1, \ldots, 10\right)$ and the average $P M$ concentrations per class are presented in Table 1

To perform pairwise comparisons of the $P M$ concentrations means across $L U C_{k}$ classes, the pairwise comparisons method for unequal sample sizes, known as Tukey's method, was performed. This approach can be applied simultaneously to all comparisons $\left\{L U C_{k}-L U C_{l}\right\}$; it is based on the studentized range distribution $q_{r, s}$ with $r$ and $s$ degrees of freedom. The null hypothesis postulates equal population means; given $I$ samples, denoting by $x_{L}$ and $x_{S}$ the largest and smallest sample means respectively, by $n_{L}$ and $n_{S}$ the corresponding sample sizes and by $N$ the total sample size, the test statistic is formulated as:

$$
\frac{x_{L}-x_{S}}{\sqrt{\left(\frac{M S E}{2}\right)\left(\frac{1}{n_{L}}+\frac{1}{n_{S}}\right)}} \sim q_{I, N-I} .
$$

Using this test statistic, the null hypothesis $H_{0}: L U C_{k}-L U C_{l}=0$ versus the alternative $H_{1}: L U C_{k}-L U C_{l} \neq 0$ for $k, l=1, \ldots, 10, l>k$ was tested. $L U C_{k}$ and $L U C_{l}$ are significantly different at level $\alpha$ if:

$$
\left|\bar{x}_{k}-\bar{x}_{l}\right| \geq q_{I, N-I, 1-\alpha} \sqrt{\left(\frac{M S E}{2}\right)\left(\frac{1}{n_{L}}+\frac{1}{n_{S}}\right)}
$$


formed based on statistically significant differences between means of $P M 10$ concentrations:

1. Agricultural - Semi-natural areas - Wetlands

2. Sports and leisure facilities

230

cover raster map is shown in Fig. 4(b).

After land cover classes were merged, a linear regression with $L U C$-specific intercepts and $S V F$ as a continuous predictor was applied to log-transformed average daily $P M 10$ concentrations:

$\log \left(P M_{i j}\right)=\alpha_{0} \cdot S V F_{i}+\sum_{k=1}^{6} \alpha_{k} \cdot \mathbb{1}\left(L U C_{i}=k\right)+\epsilon_{i j}, \quad i=1, \ldots, M, j=1, \ldots, n_{i}$

where $P M_{i j}$ denotes $P M$ concentration observed at measurement site $i$ on day $j, L U C_{i}$ and $S V F_{i}$ represent $L U C$ category and $S V F$ at site $i, \epsilon_{i j}$ represents 
the error term, which is assumed to be independently distributed as $\mathcal{N}\left(0, \sigma^{2}\right)$, available observations at site $i$.

$S V F$ and $L U C$ were statistically significant explanatory variables $(p<0.001$ for all t statistics). Notably, the estimated coefficient for SVF in Eq 3 was negative, which is in accordance with prior expectations: higher levels of sky view

atmosphere which is expected to result in reduced $P M$ concentrations observed at that particular location. Thus, interpolation of the residuals obtained from Eq 3 was performed, in addition to kriging of raw and log transformed data. The logarithmic transformation was adopted in Eq.3, as residuals of the transto address the difference in spatial support of in situ $P M$ and satellite-derived predictors. The latter were not associated with the original $P M$ data which were of point support, but with their block-kriged counterparts, in accordance with the methodology presented in Young et al. (2009). Kriging predicts unob$\left\{\boldsymbol{s}_{\mathbf{1}}, \boldsymbol{s}_{\mathbf{2}}, \ldots, \boldsymbol{s}_{\boldsymbol{n}}\right\}$. Using $\boldsymbol{Z}=\left(Z\left(\boldsymbol{s}_{\mathbf{1}}\right), \ldots, Z\left(\boldsymbol{s}_{\boldsymbol{n}}\right)\right)^{T}$ to represent $P M$ concentrations at points of $D \subset \mathbb{R}^{d}$, the predictor of $Z(\cdot)$ at a point $s_{0}$ is denoted by $p\left(\boldsymbol{Z} ; \boldsymbol{s}_{\mathbf{0}}\right)$. Ordinary Kriging (Cressie, 1993) refers to spatial predictor under the 
following two assumptions:

1. Model Assumption

$$
Z(s)=\mu+\delta(s), \quad s \in D, \mu \in \mathbb{R}, \text { and } \mu \text { unknown. }
$$

2. Predictor Assumption

$$
p\left(\boldsymbol{Z} ; \boldsymbol{s}_{\mathbf{0}}\right)=\sum_{i=1}^{n} \lambda_{i} Z\left(\boldsymbol{s}_{\boldsymbol{i}}\right), \quad \sum_{i=1}^{n} \lambda_{i}=1 .
$$

The condition that coefficients sum to 1 guarantees uniform unbiasedness, i.e.

$$
E\left[p\left(\boldsymbol{Z} ; \boldsymbol{s}_{\mathbf{0}}\right)\right]=E\left[\sum_{i=1}^{n} \lambda_{i} Z\left(\boldsymbol{s}_{\boldsymbol{i}}\right)\right]=\mu \text { for all } \mu \in \mathbb{R}
$$

and an optimal predictor $p\left(\cdot ; \boldsymbol{s}_{\mathbf{0}}\right)$ is derived by minimizing mean-squared prediction error

$$
\sigma_{e}^{2}=E\left[Z\left(\boldsymbol{s}_{\mathbf{0}}\right)-p\left(\boldsymbol{Z} ; \boldsymbol{s}_{\mathbf{0}}\right)\right]^{2}
$$
over $\left(\lambda_{1}, \ldots, \lambda_{n}\right)$, subject to $\sum_{i=1}^{n} \lambda_{i}=1$.

The need for models that interpolate $P M$ based on valid space-time covariance structures has been highlighted in Liu et.al (2009). Following Gräler et al. (2011) and Gräler et al. (2013), where the potential of different approaches for spatio-temporal interpolation of PM10 concentrations was investigated, this work evaluated two alternative methods: 2-D - ordinary kriging using separate daily variograms and 3-D - metric kriging. In the first case the semivariogram is defined as:

$$
\gamma(\boldsymbol{h})=\frac{1}{2} \cdot \mathbb{E}[Z(\boldsymbol{s})-Z(\boldsymbol{s}+\boldsymbol{h})]^{2}
$$

where $\boldsymbol{s}=\left(x_{1}, x_{2}\right)$, with $x_{1}$ representing Northing and $x_{2}$ Easting. Thus, in this case spatial dependence patterns are allowed to change on a daily basis. 3 -D kriging extends the 2-dimensional geographical space to a 3-dimensional space-time environment. Hence, $P M$ is described as a function of $x_{1}, x_{2}$ and time $t$ :

$$
Z=Z\left(x_{1}, x_{2}, t\right)=Z(s, t)
$$


with the semivariogram:

$$
\gamma(\boldsymbol{h}, \Delta)=\frac{1}{2} \cdot \mathbb{E}[Z(\boldsymbol{s}, t)-Z(\boldsymbol{s}+\boldsymbol{h}, t+\Delta)]^{2} .
$$

To obtain meaningful results from isotropic covariance models in 3-D kriging, the temporal domain had to be rescaled to match the spatial one. Since the number of stations and the locations of stations measuring $P M$ were changing from year to year, the scaling parameter that influences the spatio-temporal covariance had to be determined for each year separately. To this end, a procedure similar to the one proposed in Gräler et al. (2013) was followed. First, pure spatial and pure temporal pooled (Gräler et al., 2011) variograms were estimated and a heuristic scaling parameter was computed taking the fraction of both. Then a vector of scales ranging from $10 \mathrm{~km} /$ day to $20 \mathrm{~km} /$ day with a 500 $m /$ day step (suggested from the previous results) was created, and the optimal scale was selected by leave-one-station-out cross-validation: the data of one validation site was separated from the training sites and the model was developed based on the training sites to predict PM concentrations at the validation site. This process was repeated until each of the spatial locations was tested (exactly once). The following performance metrics were examined: Mean Error $(M E)$, which is a measure of bias, Root Mean Square Error (RMSE), Mean Absolute Error (MAE) and Pearson's Correlation Coefficient $(R)$.

In 3-D kriging, interpolation is not restricted to single time slices, since estimation is based on a selected maximum number of nearest neighbours in the space-time cube. In the present study, four maximum values $(10,100,500$ and 1000) of neighbours were evaluated. The above procedure was repeated for 3 widely used semivariogram forms: spherical, exponential and Gaussian. Finally, average concentrations per $(100 m \times 100 m)$ block were computed by block kriging (Cressie, 1993): a fine grid was placed across each block and ordinary kriging 305 was used to estimate values at each point on the grid. Then, estimated values at grid points within each block were averaged, to obtain the estimated value for the whole block. The aforementioned method has been used in previous works to associate data with different spatial supports (i.e. Gotway and Young, 2002). 
A disadvantage of the adopted method is the assumption of a metric covari-

ance model that neglects the distinction between spatial and temporal domains. An advantage is that it handles easily missing data at any location for a given day, using information from the previous and the following days. Furthermore, it can be applied to a small number of in situ observations, which was the case for PM2.5 concentrations. In this case, 2-D kriging resulted in singular variogram models, which neglect spatial dependencies.

Raw and log-transformed data, as well as residuals computed from Eq3 were interpolated to obtain an estimated average value for each $100 \mathrm{~m} \times 100 \mathrm{~m}$ block surrounding a particular $P M$ station. In general, the kriging predictor is asymptotically unbiased and gives the correct estimate when applied to raw $P M$ concentrations. When applied to $\log$-transformed $P M, Y(s)$ were backtransformed using the equation:

$$
Z(s)=\exp \left(Y(s)+\frac{\sigma^{2}(s)}{2}\right)
$$

with $\sigma^{2}(s)$ denoting the bias-correction factor (Denby et al. 2008). When residuals are interpolated, $Y(s)$ represents the estimate which combines regression predictions with kriged residuals. $Z(s)$ represents estimated $P M$ concentrations at a $100 m \times 100 m$ resolution, denoted by $P M[$ kriged $]$ in the following. ${ }_{20}$ Finally, to comply with the MERIS/AATSR synergy derived AOT, the kriged $100 \mathrm{~m} \times 100 \mathrm{~m}$ surface was up-scaled at $1 \mathrm{~km} \times 1 \mathrm{~km}$ resolution averaging for every $10 \times 10$ cell.

\subsection{Linear Mixed-Effects Models: day-specific random effects}

Data homogenization with regard to spatial support and geographic projec325 tion was followed by an evaluation of the predictive capability of Linear MixedEffects Models with day-specific random effects (LMM1). This model class was proposed in Lee et al. (2011) to better capture the large daily variability in the $A O T-P M$ relationship. In this article $L M M 1$ was based on the following satellite-derived predictors: the high-resolution MERIS/AATSR synergy derived $A O T$ product, KIND and meteorological variables STMP, RHUM. 
Satellite-derived covariates displayed clear seasonal patterns; in order to work with data which is stationary in mean (Cowpertwait and Metcalfe, 2009), for each covariate, deviations from its estimated annual profile were computed. Annual profiles were estimated by fitting a sinusoid to the time series:

$$
E[X(t)]=a+b \cdot \sin \left(\frac{2 \pi}{365.25}\left(t+t_{0}\right)\right)
$$

where $t$ is the Julian Day of the year, $X(t)$ denotes observed AOT, STMP, $R H U M$ or $K I N D$ at day $t$, and $a, b, t_{0}$ denote unknown coefficients.

Figure 6 depicts estimated seasonal profiles using Nonlinear Least Squares (NLS) and Nonlinear Absolute Deviations (NAD) together with the derived equations for the NLS case. The performance of median regressions (which corresponds to NAD) was similar to the one achieved by conventional mean regression which suggests the absence of outlying measurements. Moreover, since deviations from annual profiles, denoted by DevAOT, DevSTMP, DevRHUM and DevKIND, were better explaining the variability of $P M$ in the performance evaluation of mixed-effects models, further analyses refer to them.

The model-building procedure for mixed-effects models decides which coefficients need random effects to account for their between-day variation and which coefficients can be treated simply as fixed effects. In the analyses presented in the following sections, the protocol proposed in Pinheiro and Bates (2006) and Zuur et al. (2009) was adopted. Comparisons between models with different random effects structures was based on Anova tests, as well as on the Akaike (AIC) and the Bayesian Information Criteria (BIC). The interested reader may consult Pinheiro and Bates (2006) and Zuur et al. (2009) for further details on model building and estimation of mixed effects models. The general model is based on the following formulation:

$$
\begin{aligned}
& \log \left(P M\left[\text { kriged }_{i j}\right)=\left(\beta_{0}+b_{0, j}\right)+\beta_{0, k} M O_{k}+\beta_{0, l} D W_{l}+\left(\beta_{1}+b_{1, j}\right) D e v A O T_{i j}+\right.
\end{aligned}
$$

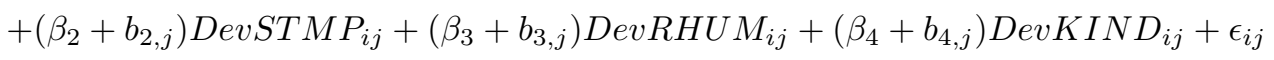




$$
\text { with: } \quad\left(\begin{array}{c}
b_{0, j} \\
b_{1, j} \\
b_{2, j} \\
b_{3, j} \\
b_{4, j}
\end{array}\right) \sim \mathcal{N}\left(\left(\begin{array}{c}
0 \\
0 \\
0 \\
0 \\
0
\end{array}\right), \Psi\right) \text { and } \epsilon_{i j} \sim \mathcal{N}\left(0, \sigma^{2}\right) \text {, }
$$

where $P M\left[\right.$ kriged $_{i j}$ denotes block-kriged $P M$ concentration observed at spatial site $i$ on day $j, D_{e v A O T_{i j}}$,DevSTMP $P_{i j}, \operatorname{DevRHU} M_{i j}$, DevKIND $D_{i j}$ represent respectively, deviations from the seasonal profiles of AOT, STMP, RHUM, and $K I N D$, at site $i$ on day $j, \beta_{0}$ and $b_{0, j}$ correspond to coefficients for the fixed and random intercepts, whereas $\beta_{1}, \beta_{2}, \beta_{3}, \beta_{4}$ and $b_{1, j}, b_{2, j}, b_{3, j}, b_{4, j}$ denote the fixed and random slopes, respectively. $M O_{k}$ and $D W_{l}$ are dummy variables for months and days of the week $(k=2, \ldots, 12$ and $l=1, \ldots, 7)$, with $\beta_{0, k}$ and $\beta_{0, l}$ denoting the corresponding coefficients. $\boldsymbol{\Psi}$ is the variance-covariance matrix for the day-specific random effects and $\epsilon_{i j}$ represents the error terms. The full general model included all 2-way interactions of the fixed-effects which are omitted in Eq. 13 for brevity.

The fixed effects $\beta_{0}-\beta_{4}, \beta_{0, k}$ and $\beta_{0, l}$ in Eq 13 represent the mean values of model parameters. $L M M 1$ focuses on temporal instability in the association between satellite-derived and in situ measurements: day-specific deviations are represented by the random effects $b_{0, j}-b_{4, j}$, which are assumed to follow a multivariate normal distribution characterized by $\boldsymbol{\Psi}$. Random effects corresponding to different days are assumed to be independent; this is a limitation of $L M M 1$. Day-specific errors $\epsilon_{i j}$ are assumed to be normally distributed and independent of the random effects.

\subsection{Linear Mixed-Effects Model: site-specific random effects}

$L M M 1$ is based on daily $P M$ measurements and cannot be used to produce $P M$ maps in days which lack in situ measurements, as the corresponding random effects cannot be estimated. To address this issue, Linear Mixed-Effects Models with site-specific random effects (dubbed $L M M 2 a$ ) were developed and their predictive capability was evaluated. $L M M 2 a$ focuses on spatial instability in the 
association between satellite-derived and in situ measurements: random effects correspond to site-specific deviations from the mean value of the coefficients. In this case, it is the available measurement positions that are treated as a sample from a population.

The model-building procedure applied for $L M M 1$ was performed again, to evaluate fixed and site-specific random effects; furthermore, auto-correlated location-specific errors were taken into account. Due to a large number of missing days with available satellite-derived products, leading to in situ measurements not equally spaced in time, a continuous autoregressive structure was used. This structure fits a continuous first-order autoregressive process: the correlation between errors $\epsilon_{i, t}$ and $\epsilon_{i, t+\Delta t}$ observed at location $i$ is expressed as $\rho(\Delta t)=\phi^{|\Delta t|}$, with $0 \leq \phi<0$ (Pinheiro and Bates, 2006). The general model was based on the following formulation:

$$
\begin{gathered}
\log \left(P M[\text { kriged }]_{i j}\right)=\left(\beta_{0}+b_{0, i}\right)+\beta_{0, k} M O_{k}+\beta_{0, l} D W_{l}+\left(\beta_{1}+b_{1, i}\right) \text { DevAOT } i j+ \\
+\left(\beta_{2}+b_{2, i}\right) \text { DevSTMP } P_{i j}+\left(\beta_{3}+b_{3, i}\right) \text { DevRHUM } M_{i j}+\left(\beta_{4}+b_{4, i}\right) \text { DevKIND } D_{i j}+\epsilon_{i j}
\end{gathered}
$$

370

with: $\left(\begin{array}{c}b_{0, i} \\ b_{1, i} \\ b_{2, i} \\ b_{3, i} \\ b_{4, i}\end{array}\right) \sim \mathcal{N}\left(\left(\begin{array}{c}0 \\ 0 \\ 0 \\ 0 \\ 0\end{array}\right), \Psi\right)$ and $\epsilon_{i, j}=\phi_{1} \cdot \epsilon_{i, j-\Delta t}+a_{i j}$, where $a_{i j} \sim \mathcal{N}\left(0, \sigma^{2}\right)$

$\beta_{0}-\beta_{4}, \beta_{0, k}$ and $\beta_{0, l}$ represent mean values of the parameters in the population of measurement sites. The random effects $b_{0, i}-b_{4, i}$ account for location-specific deviations in the association between satellite and in situ measurements and are assumed to follow a normal distribution with variance-covariance matrix $\Psi$. 375 Again, the full model included two-way interactions of the covariates which are not shown.

In Eq.14 the K-Index, an atmospheric static stability estimator, was used as a continuous covariate. In previous studies it has been used as a categorical 
variable (e.g Chrysoulakis et al. 2004; Benas et al., 2013b). Therefore, another model (labeled $L M M 2 b$ ) was tested, using the K-Index as a dichotomous indicator of aerosol vertical mixing height. Specifically, a 2-regime model with site-specific random intercepts and random slopes was tested. The first regime was corresponding to atmospheric static instability (suggested by high values of the K-Index) and the second was related to static stability (low K-Index values). To estimate the optimal value of $K I N D$ that separates the two regimes, a threshold regression model (Hansen, 2000) was estimated:

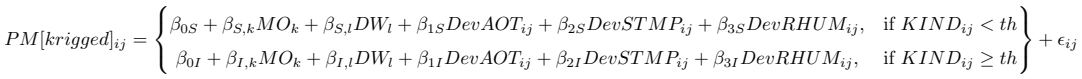

where $S$ corresponds to the static stability, $I$ corresponds to instability and $t h$ represents the estimated threshold. Again, two-way interactions were included in the fixed effects part and site-specific random terms were evaluated using the forward stepwise procedure which takes into account auto-correlated locationspecific errors.

5-fold cross validation was performed to gauge the quality of both mixedeffect models: the dataset was repeatedly randomly divided into $80 \%$ (training set) and $20 \%$ (test set) splits; predictions for the test set were made using the estimated model from the training set. Moreover, leave-one-pixel-out crossvalidation was applied to evaluate the generalization capability of the model to any grid-cell of the study domain. This evaluation is similar to leave-one-stationout, described in the previous section for kriging. The difference is that instead of in situ measurements, block-kriged $P M$ concentrations at pixels that contain measurement stations were used. In all cross-validation experiments, the out of sample predictive performance was evaluated based on $R^{2}, M E, M A E$, mean $(M A P E)$ and median $(M D A P E)$ absolute percentage errors.

\section{Results and Discussion}

\subsection{Descriptive Statistics}

395

Table 4 presents average annual PM10 and PM2.5 concentrations measured at London's Air Quality stations during the 2002 - 2012 study period, and the 
number of measurement stations per year. Average annual PM10 concentrations ranged from $24.91 \mu \mathrm{gm}^{-3}$ in 2010 to $32.04 \mu^{-3} m^{-3}$ in 2003 and PM2.5 concentrations ranged from $13.59{\mu \mathrm{gm}^{-3}}$ in 2002 to $16.18 \mu \mathrm{gm}^{-3}$ in 2007. The number of stations that provide PM2.5 quintupled from 2002 to 2012 whereas the number of stations that provide PM10 ranged from 52 in 2002 to 77 in 2006.

Though, as mentioned above, the particular study domain was chosen for its dense in situ $P M$ measuring stations network, the main disadvantage of this area is the large percentage of missing satellite-derived $A O T$ observations due to cloud cover, especially in winter. Another drawback is the poor temporal resolution of the MERIS and AATSR sensors (one acquisition per 2-3 days). Both these reasons, combined with the algorithm's quality criteria, resulted in valid data for 358 days for the 11-year study period. The average daily AOT values varied from 0.03 to 0.77 with higher values in the warm season and lower in the cold season.

The results of any statistical estimation technique should be interpreted in the context of the uncertainty and variability of the estimated products. In our case, two sources of uncertainty had to be considered: the first was caused by the estimation of areal $P M$ concentrations from in situ measurements using kriging, that led to the use of estimated values instead of observed $P M$ concentrations in the regression model. The second source of uncertainty was caused by estimation of the regression coefficients in the mixed-effects models. In the following, we present results separately for each source of uncertainty.

\subsection{Estimation of PM10}

\subsubsection{Kriging}

2-D kriging relied on a day-specific variograms, whilst 3-D metric kriging relied on a single variogram per year. Preliminary investigations based on crossvalidation suggested that the spherical variogram $(\mathrm{Eq} .16)$ captured spatial and spatio-temporal dependencies more effectively, compared to exponential and 
Gaussian variograms; therefore, it was adopted in all further analyses:

$$
\gamma(\boldsymbol{h})=p s \cdot\left(\left(\frac{3\|\boldsymbol{h}\|}{2 r}-\frac{\|\boldsymbol{h}\|^{3}}{2 r^{3}}\right) \mathbb{1}_{(0, r)}(\|\boldsymbol{h}\|)+\mathbb{1}_{[r, \infty)}(\|\boldsymbol{h}\|)\right)+n \mathbb{1}_{(0,+\infty)}(\|\boldsymbol{h}\|)
$$

The parameters ps (Partial Sill), $n$ (Nugget) and $r$ (Range) in Eq 16 were estimated using the R-package gstat (Pebesma, 2004). The results of leave-onestation-out cross validation in case of 2-D ordinary kriging are summarized in ${ }_{425}$ Table 5. The best performing method is based on interpolation of the residuals obtained from multiple regression of log-transformed PM10. For 3-D kriging, the best performance in the cross-validation experiment, was achieved by taking at most 100 neighbours to estimate $P M$ at a given location. The outcome was markedly inferior for 10 neighbours, whereas the use of 500 and 1000 neighbours showed small improvements, increasing immensely computational time. The estimated variogram parameters, the scales that resulted in optimal crossvalidation results (on a daily level) and the corresponding performance metrics are presented in Table 6. Annual differences in estimated parameters are influenced by changes in the number of available measurements per air quality station, and the variability in distances between these stations.

口 Results are similar to the ones presented in Gräler et al. (2011) and Gräler et al. (2013), outperforming them for some years, which should be expected since in the present study metric-kriging was applied at a completely different scale, having much smaller spacing distance between pairs of stations. Another explanation is the use of $L U C$ and $S V F$ static datasets in multiple regression, which aimed to account for local emission, sequestration and diffusion of the particles. Cross-validation results suggest that 3-D kriging outperformed 2-D kriging only in terms of bias. The levels of accuracy achieved from 3-D kriging were close to the ones achieved using daily variograms, leading to a smoother $P M$ kriged surface and thus being closer to the satellite observations at $1 \mathrm{~km} \times$ $1 \mathrm{~km}$. Moreover, the large local variability observed in $P M 10$ concentrations and the small number of in situ stations measuring $P M 2.5$, resulted in singular daily variogram models. Therefore, in the estimation of mixed-effects models that will follow, interpolated values using 3-D kriging were used. 

$P M$ concentrations at every $100 m \times 100 m$ cell. The resulting surface was upscaled to $1 \mathrm{~km} \times 1 \mathrm{~km}$ spatial resolution by computing the mean value for every $10 \times 10$ block. Figures 7(a) and7(b) show an example of kriged $P M 10$ surface for the whole study area, before and after upscaling; in this case no information from satellite-derived products was used. In Figure 7)(a) one may observe the effect of $L U C$ and $S V F$ on the spatial distribution of $P M$ concentrations: higher particle concentrations are ascertained in areas that generate emissions (e.g. continuous urban fabric and port areas) with low $S V F$ values, which lead to constrained dispersion in the urban canopy. In practice, the satellite-derived $A O T$ used in this study cannot capture the fine-scale and local-scale emissions, and the up-scaled figure is more likely what MERIS and AATSR "see". The results presented next were based on block-kriged values for $1 \mathrm{~km} \times 1 \mathrm{~km}$ cells surrounding $P M$ stations.

\subsubsection{Linear Mixed-Effects Models}

465

Figure 8(a) depicts a scatter-plot of MERIS/AATSR derived AOT values versus 3 -D kriged $P M 10$ concentrations at $1 \mathrm{~km} \times 1 \mathrm{~km}$ blocks surrounding each station, during the 2002-2012 time period. It is evident that near surface $P M 10$ concentrations are not strongly correlated with total $A O T$ column values $(R=0.28)$. AOT represents columnar aerosol from the surface to the top of the atmosphere, while PM10 mass concentration corresponds to suspending particles with diameter less than $10 \mu m$ close to the surface. Subsequently, $A O T$ is not representative of $P M 10$ measurements, since $P M 10$ is not uniformly distributed in the vertical column.

The model building procedure for $L M M 1$ resulted in significant random effects, with high standard deviations for intercepts and DevAOT slopes. The likelihood ratio test indicated that the model with day-specific random intercepts was significantly improved relative to the general fixed-effects model, with $L=16897.897(d f=1, p$-value $<0.001)$. The AIC and BIC scores were also substantially smaller: 37665.11 and 37713.21 , respectively, compared 
to 54561.00 and 54602.23. The same conclusions were drawn for the inclusion of day-specific random slopes for DevAOT, DevSTMP, DevRHUM and DevKIND with $A I C=37016.71$ and $B I C=37161.02$ for the optimal random structure. ML estimation, used for comparison of models with nested fixed effects and the same random structure, resulted in significant (at $p$-value $<0.001$ ) fixed intercept and fixed DevSTMP and DevRHUM slopes, leading to the following form:

$$
\begin{aligned}
\log \left(P M 10\left[\text { kriged }_{i j}\right)=(3.22+\right. & \left.b_{0, j}\right)+b_{1, j} \text { DevAOT } i j \\
& +\left(0.04+b_{2, j}\right) \text { DevSTMP } P_{i j}+ \\
& +\left(0.004+b_{3, j}\right) \text { DevRHUM }+b_{4, j} \text { DevKIND } D_{i j}+\epsilon_{i j}
\end{aligned}
$$

with: $\Psi=\left[\begin{array}{rrrrr}0.38 & 0.15 & 0.05 & 0.05 & -0.13 \\ 0.15 & 0.29 & 0.18 & 0.27 & 0.16 \\ 0.05 & 0.18 & 0.06 & 0.72 & -0.59 \\ 0.05 & 0.27 & 0.72 & 0.02 & -0.52 \\ -0.13 & 0.16 & -0.59 & -0.52 & 0.03\end{array}\right]$ and $\epsilon_{i j} \sim \mathcal{N}(0,0.009)$.

It should be noted that the diagonal elements of $\boldsymbol{\Psi}$ report standard deviations and the off-diagonal elements report correlations instead of covariances as correlations are more useful for diagnostic purposes (strongly correlated random effects suggest over-parameterized models).

The (out of sample) predictive performance of $L M M 1$ (Fig. 8 b) was satisfactory: 5-fold cross-validated $R^{2}=0.95$, with $M A E, M A P E$ and $M D A P E$ considerably small (Table $8 L M M 1$ part, 1st column). Moreover, cross-validation results suggest that estimations were unbiased $(M E=0.12)$ which is important when producing estimates to support risk assessment and epidemiological studies. The leave-one-pixel-out cross-validation experiment used to examine whether the model could be generalized to any grid cell in the study domain 485 performed equally well. The 2 nd column of Table 8 ( $L M M 1$ part) presents site-specific comparisons between kriged and estimated PM10 concentrations using $L M M 1$. Results suggest that estimations are reliable for the majority of spatial sites. 
For $L M M 2 a$, the model building procedure did not result in significant random effects, with the intercept being the only coefficient displaying significant location-specific deviations. The likelihood ratio test, as well as AIC and BIC values, indicated that site-specific random slopes for satellite-derived products were not significant, leading to unnecessary model complexity. This is supporting the hypothesis stated in Lee et al. (2011): parameters influencing the relationship between $P M$ and $A O T$ do not display significant spatial variability. AIC and BIC scores suggested that the model with autoregressive residual structure was highly significant, hence it was kept in the optimal random structure. The fitted model is formulated as follows:

$$
\begin{aligned}
& \log \left(P M 10\left[\text { kriged }_{i j}\right)=\left(3.28+b_{0, i}\right)-0.05 W P+0.07 M o n+1.24 \text { DevAOT }_{i j}+\right. \\
& \text { +0.03DevSTMP } P_{i j}+0.002 \text { DevRHU } M_{i j}-0.02 \operatorname{DevKIND_{ij}-} \\
& -0.22 W P: \operatorname{DevAOT}_{i j}+0.03 W P: \operatorname{DevTEM} P_{i j}+0.02 W P: \operatorname{DevKIN} D_{i j}+\epsilon_{i j}
\end{aligned}
$$

where $W P$ is a dummy variable that represents the warm season (May to October), Mon a dummy variable for Mondays, $b_{0, i} \sim \mathcal{N}(0,0.004), \epsilon_{i, j}=$ $0.57 \cdot \epsilon_{i, j-\Delta t}+a_{i j}$ and $a_{i j} \sim \mathcal{N}(0,0.10)$.

It is interesting to note that the model in Eq 18 contains season-specific effects for all satellite-derived covariates except DevRHUM. The first two columns in Table 8 ( $L M M 2 a$ part) depict the corresponding values of $M E$, ${ }_{495} M A E, M A P E$ and $M D A P E$, using both cross-validation methods. The outcome is clearly inferior relative to $L M M 1$; this result manifests the effect of avoiding daily calibration of satellite-derived products with in situ $P M$ concentrations.

The 2-regime analysis resulted in a K-Index threshold equal to $t h=280$, with $43 \%$ of the observations below the threshold. $L M M 2 b$ is formulated as 
follows:

$$
\begin{aligned}
& \log \left(P M 10\left[\text { kriged }_{i j}\right)=\left(3.25+b_{0, i}\right)-0.05 W P+0.07 M o n+1.24 \text { DevAOT } T_{i j}+\right. \\
& +0.02 \operatorname{DevSTMP} P_{i j}+0.005 \operatorname{DevRHU} M_{i j}-0.03 \operatorname{DevKIND_{ij}-} \\
& -0.19 W P: D^{2} A O T_{i j}+0.01 W P: \operatorname{DevSTMP} P_{i j}+0.02 W P: \operatorname{DevKIND_{ij}+}
\end{aligned}
$$

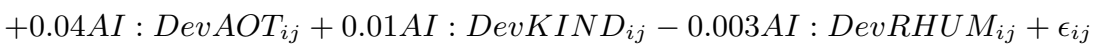

with $A I$ a dummy variable that represents Atmospheric Instability $(K I N D>$

$P M 10$ was used, since pairwise comparisons of average $P M 2.5$ concentrations didn't lead to statistically significant results. 
Preliminary investigations based on a cross-validation experiment suggested that the spherical variogram was again the best performing model in capturing space-time dependencies of PM2.5 concentrations. The estimated parameters $p s, n$ and $r$, the scales giving best cross-validation results per day and the corresponding performance metrics are presented in Table 7. Figures 7(c) and 7(d) show an example of the kriged surface for the whole study area, before and after up-scaling. As expected, the small number of in situ PM2.5 measurements and the fact that daily satellite-derived covariates have not been taken into account at this stage, resulted in a non-representative image for the whole domain. Again, only the kriged values at cells containing $P M$ stations were used in further analyses.

\subsubsection{Linear Mixed-Effects Models}

Figure 8(c) shows the scatter-plot between available $A O T$ values and kriged $P M 2.5$ concentrations at $1 \mathrm{~km} \times 1 \mathrm{~km}$ blocks surrounding each station during the study period. Again, there was weak correlation $(R=0.19)$ between near surface PM2.5 concentrations and columnar AOT values. Once more, a significant improvement was achieved by applying $L M M 1$ (Fig, 8 (d) and 3rd column of Table 8, LMM1 part). The estimated model took the following form:

$$
\begin{array}{r}
\left.\log (\text { PM2.5[kriged }]_{i j}\right)=\left(2.65+b_{0, j}\right)+b_{1, j} \text { DevAOT }_{i j}+b_{2, j} \text { DevSTMP } P_{i j} \\
+0.04 W P: \text { DevSTMP } P_{i j}+b_{4, j} \text { DevKIND } D_{i j}+\epsilon_{i j} \\
\text { with: } \Psi=\left[\begin{array}{rrrr}
0.38 & -0.05 & 0.42 & -0.17 \\
-0.05 & 0.35 & -0.51 & -0.65 \\
0.42 & -0.51 & 0.04 & 0.45 \\
-0.17 & -0.65 & 0.45 & 0.02
\end{array}\right] \text { and } \epsilon_{i j} \sim \mathcal{N}(0,0.02) .
\end{array}
$$

Notably, Eq20 suggests stronger effects of temperature in the warm season, which was not observed for PM10 in Eq17. The model displayed satisfactory out of sample performance with $R^{2}>0.85$ for both 5 -fold and leave-one-pixelout cross-validations. $M A E, M A P E$ and $M D A P E$ were larger relative to what 
was observed for PM10 with accuracy, defined as $1-M A P E$, close to $90 \%$ and low bias $\left(M E=0.25 \mu \mathrm{gm}^{-3}\right)$.

In accordance to what was observed in the predictive models for PM10, the model building procedure for $L M M 2 a$ and $L M M 2 b$ resulted in significant random intercepts; that is, location-specific variations in the effects of satellitederived predictors were not statistically significant. $L M M 2 a$ and $L M M 2 b$ are formulated as follows:

$$
\begin{aligned}
& \log \left(\text { PM2 }_{2.5}\left[\text { kriged }_{i j}\right)=\left(2.69+b_{0, j}\right)+1.86 \operatorname{DevAOT} T_{i j}+0.06 \operatorname{DevSTMP_{ij}-}\right. \\
& -0.03 D e v K I N D_{i j}-0.97 W P: D e v A O T+0.03 W P: D e v K I N D \epsilon_{i j}
\end{aligned}
$$

with $b_{0, i} \sim \mathcal{N}(0,0.008), \epsilon_{i, j}=0.58 \cdot \epsilon_{i, j-\Delta t}+a_{i j}$ and $a_{i j} \sim \mathcal{N}(0,0.13)$.

and

$$
\begin{aligned}
& \log \left(\text { PM2 }_{2}\left[\text { kriged }_{i j}\right)=\left(2.64+b_{0, j}\right)+2.03 \text { DevAOT } T_{i j}+0.04 \text { DevSTMP } P_{i j}-\right. \\
& -0.03 \operatorname{DevKIND} D_{i j}-0.70 W P: \operatorname{Dev} A O T+0.03 W P: \text { DevKIND- } \\
& -0.56 A I: D_{\text {ev } A O T_{i j}}+0.02 A I: \operatorname{DevSTMP}_{i j}+0.01 A I: \operatorname{DevKIN} D_{i j}+\epsilon_{i j}
\end{aligned}
$$

with $b_{0, i} \sim \mathcal{N}(0,0.004), \epsilon_{i, j}=0.55 \cdot \epsilon_{i, j-\Delta t}+a_{i j}$ and $a_{i j} \sim \mathcal{N}(0,0.10)$.

The predictive performance of $L M M 2 a$ and $L M M 2 b$ is inferior relative to $L M M 1$ (Table 8, $L M M 2 a$ and $L M M 2 b$ parts). Again, a small improvement of the performance metrics in the cross-validation experiment was achieved when the K-Index was used as a dichotomous estimator of aerosol vertical mixing height. The estimated AOT slopes for the two regimes (high versus low atmospheric instability) are significantly different; this can be attributed to diverse mixing conditions of the aerosols under stable or unstable atmospheric conditions. In contrast to what was observed for PM10, the effects of DevRHUM were not statistically significant in $L M M 2 a$ and $L M M 2 b$. 5-fold MAE increased from 5.21 to $6.48 \mu^{-3}$ when all satellite derived covariates were removed (5.66 when only $A O T$ was removed).

\subsection{Discussion}

Previous studies that focused on the estimation of the spatial distribution of particulate matter concentrations, were mostly performed on large scales, 
relying on $10 \mathrm{~km} \times 10 \mathrm{~km}$ AOT from MODIS. Practitioners such as urban planners, as well as epidemiologists are interested in estimating the spatial distribution of daily mean $P M$ concentration at finer scales. The results of the cross-validation experiments presented in the previous sections, showed that application of mixed-effects models with day-specific random effects using high resolution $(1 \mathrm{~km} \times 1 \mathrm{~km})$ satellite-derived products, has the potential to meet their needs.

Regression-kriging (2-D and 3-D) could be used to produce high-resolution daily $P M$ maps for the entire study area, based on in-situ $P M$ measurements, $L U C$ and $S V F$ static data, which account for local industrial, domestic and traffic related air pollution. However, in this case, no information from satellitederived products is used, leading to non-representative maps when a small number of in-situ PM measurements is available. The use of AOT, RHUM, STMP and $K I N D$ allowed better assessment of the spatio-temporal dynamics of $P M$, since these predictors captured differences in particulate matter concentrations among grid cells. Hence, daily calibration of satellite products with block-kriged $P M$ in areas close to air-quality stations, can be used to produce urban $P M$ maps, which are relevant in studies that associate $P M$ to short-term acute effects of air pollution.

575 The results of mixed-effects models with day-specific random effects are comparable to the ones presented in Nordio et al. (2013) for estimation of PM10 and in Kloog et al. (2011) for estimation of PM2.5 concentrations. Improved out of sample performance metrics can be attributed to the use of block-kriged instead of in situ $P M$ concentrations as the variability of spatial averages is reduced relative to the variability of measurements with point-level support. On the other hand, mixed-effects models with site-specific random effects, which can be transferred to areas with no daily in situ data, displayed inferior predictive performance. Application of such models is promising though, in view of the fast evolving satellite remote sensing products. Reassessment of these models using satellite observations with higher temporal resolution and better data quality, is expected to lead to improved performances. 
The operational application of $L M M 1$ for a new day $J$, requires both in situ and satellite measurements, data homogenization (Sections 4.2.1 and 4.3.1) and re-estimation of Eq17 and 20 using pixels that correspond to measurement locations, to derive the (day-specific) random effects $b_{0, J}-b_{4, J}$. The updated version of Eq 17 and 20 can be used to produce PM10[kriged] and PM2.5[kriged $]$ for all pixels with available satellite-derived measurements. If, on the other hand, in situ data are not available, one may estimate PM10[kriged $]$ and PM2.5[kriged $]$ based solely on satellite products using directly Eq19 and 22, random intercepts can be substituted with their expected value which is zero. In such a case one should expect a substantial drop in estimation accuracy as shown in Table 8

Figure 9 (a) shows the spatial pattern of estimated average PM10 concentrations derived from the satellite observations for the entire study period (2002-2012), using mixed-effects models with day-specific random effects at ${ }_{600} 1 \mathrm{~km} \times 1 \mathrm{~km}$ resolution. Figure 9(b) shows the corresponding map for $P M 2.5$. Both maps partition concentrations into ten equally sized bins. Estimated $P M 10$ concentrations range from $27.89{\mu g m^{-3}}^{-10} 33.35 \mu g m^{-3}$, whereas estimated PM2.5 values lie between $16.25 \mathrm{\mu gm}^{-3}$ and $19.72 \mu \mathrm{gm}^{-3}$. The estimated values are slightly higher than averages observed at the stations (Table 605 44; a plausible explanation is that during the winter time fewer satellite $A O T$ products are available, which resulted in increased overall mean $A O T$ values and therefore, increased levels of estimated $P M$ concentrations. Remarkably, $L M M 1$ resulted in lower estimated $P M$ levels for agricultural and green urban areas (Categories I-II in Fig. 4b) and higher concentrations for industrial, continuous urban fabric and port areas (Categories IV-VI in Fig. 4 b) without the use of these spatial predictors in mixed-effects models; the same was observed for PM2.5 despite the small number of in situ measurements. These findings suggest that satellite-derived products are able to capture the spatial variability of $P M$ at $1 \mathrm{~km} \times 1 \mathrm{~km}$ scale in the areas of investigation. 


\section{Conclusions}

Geostatistical investigations that permit inferences relating to potential associations between satellite-based products and ground-based geophysical parameters continues to be an active topic in both research and practice. For meaningful interpretation of the association among these variables based on valid statistical inference, inhomogeneous spatial supports need to be taken into consideration.

This study estimated surface $P M 10$ and $P M 2.5$ concentrations over the area of Greater London, based on in situ PM measurements and satellite-derived covariates. The latter included AOT from the MERIS/AATSR synergy, as well as RHUM, STMP and KIND from MODIS. Moreover, LUC and SVF products were incorporated to account for the local scale emissions, sequestration and diffusion of particles between different monitoring stations. Two kriging methods were applied to in situ $P M$ measurements to take into account different spatial supports of in situ and satellite-derived observations. Predictive models based on the MERIS/AATSR derived AOT on $1 \mathrm{~km} \times 1 \mathrm{~km}$ produced satisfactory results, with accuracies (defined as $1-M A P E$ or as $1-M D A P E$ ) close to 90\% for mixed-effects models with day-specific random effects, for both PM10 and $P M 2.5$.

The first satellite of the Sentinel 3 series (the Sentinel 3A) is expected to be launched by the European Space Agency (ESA) in late 2015. The synergistic use of the Sea and Land Surface Temperature Radiometer (SLSTR) and the Ocean and Land Color Instrument (OLCI), on board Sentinel-3 satellite (Berger et al., 2012), is expected to provide improved AOT, RHUM, STMP and $K I N D$ products, and thereby increase the potential to support local scale

studies related to urban planning and public health. Furthermore, the simultaneous operation of Sentinel 3A and Sentinel 3B in the near future is expected to provide frequent observations, refining the drawback of relating daily average $P M$ to the MERIS/AATSR synergy AOT, retrieved from a single satellite acquisition. This study may contribute to the development of an operational tool 


\section{Acknowledgements}

This work was performed in the framework of the PEFYKA project within the KRIPIS Action of the General Secretariat for Research and Technology. The project is funded by Greece and the European Regional Development Fund of the European Union under the NSRF and the O.P. Competitiveness and Entrepreneurship. Anton Beloconi is grateful to the MathMods (Mathematical Modelling in Engineering) programme for partially funding this work through a scholarship. Yiannis Kamarianakis was partially supported by the National Science Foundation under Award DMS-1419593. The authors are grateful to 
three anonymous reviewers for their constructive comments, to the European Space Agency for providing MERIS and AATSR data based on the Category1 project (ID: 12018) and to the London Air Quality Monitoring Network for providing the $P M 10$ and $P M 2.5$ measurements.

\section{References}

Armstrong, M.: Basic linear geostatistics, Springer Science \& Business Media, 1998

Ballester, F., Estarlich, M., Iñiguez, C., Llop, S., Ramón, R., Esplugues, A., Lacasaña, M., and Rebagliato, M.: Air pollution exposure during pregnancy and reduced birth size: a prospective birth cohort study in Valencia, Spain, Environ. Health-Glob., 9(6), 2010.

Benas, N., Chrysoulakis, N., and Giannakopoulou, G.: Validation of MERIS/AATSR synergy algorithm for aerosol retrieval against globally distributed AERONET observations and comparison with MODIS aerosol product, Atmos. Res., 132, 102-113, 2013a.

Benas, N., Beloconi, A., and Chrysoulakis, N.: Estimation of urban PM10 concentration, based on MODIS and MERIS/AATSR synergistic observations, Atmos. Environ., 79, 448-454, 2013b.

Berger, M., Moreno, J., Johannessen, J.A., Levelt, P.F., Hansen, R.F.: ESA's sentinel missions in support of Earth system science, Remote Sens. Environ., 120, 84-90, 2012.

Borrego, C., Cascão, P., Lopes, M., Amorim, J. H., Tavares, R., Rodrigues, V., Martins, J., Miranda, A. I., and Chrysoulakis, N.: Impact of urban planning alternatives on air quality: URBAIR model application, in: WIT Transactions on Ecology and the Environment Vol 147, Brebbia C. A., Longhurst, J. W. S., Popov, V. (eds), WIT Press, United Kingdom, 1743-3541, 2014. 
mann Consult: The Earth Observation Toolbox and Development Platform BEAM, 2011. http://www.brockmann-consult.de/cms/web/beam/

Carslaw, D.C. and Ropkins K.: openair - an R package for air quality data analysis, Environ. Modell. Softw., 27-28, 52-61, 2012.

Chrysoulakis, N., Spiliotopoulos, M., Feidas, H., Domenikiotis, C. and

Chrysoulakis, N., Lopes, M., San José, R., Grimmond, C.S.B., Jones, M.B., Magliulo, V., Klostermann, J.E.M., Synnefa, A., Mitraka, Z., Castro, E., González, A., Vogt, R., Vesala, T., Spano, D., Pigeon, G., Freer-Smith, P., Staszewski, T., Hodges, N., Mills, G. and Cartalis, C.: Sustainable urban metabolism as a link between bio-physical sciences and urban planning: The

Chrysoulakis, N., Castro, E. A., Moors, E. J. (Eds): Understanding Urban Metabolism: A Tool for Urban Planning, Routledge, Taylor \& Francis, ISBN 9780415835114, London, 2014.

Chu, D. A., Kaufman, Y. J., Zibordi, G., Chern, J. D., Mao, J., Li, C., and Holben, B. N.: Global monitoring of air pollution over land from the Earth Observing SystemTerra Moderate Resolution Imaging Spectroradiometer (MODIS), J. Geophys. Res.-Atmos., 108(D21), 2003.

Cowpertwait, P.S.P. and Metcalfe A.V.: Introductory Time Series with R, Springer, 2009.

Cressie, N.: Statistics for Spatial Data, Wiley Series in Probability and Statistics, 1993. 
Denby, B., Schaap, M., Segers, A., Builtjes, P., and Horálek, J.: Comparison of two data assimilation methods for assessing PM10 exceedances on the European scale, Atmos. Environ., 42(30), 7122-7134, 2008.

Dimitrova, R., Lurponglukana, N., Fernando, H. J. S., Runger, G. C., Hyde, P., Hedquist, B. C., Anderson, J., Bannister, W., and Johnson, W.: Relationship between particulate matter and childhood asthma - basis of a future warning system for central Phoenix, Atmos. Chem. Phys., 12(5), 2479-2490, 2012.

Drury, E., Jacob, D. J., Spurr, R. J., Wang, J., Shinozuka, Y., Anderson, B. E., Clarke, A.D., Dibb, J., McNaughton, C., and Weber, R.: Synthesis of satellite (MODIS), aircraft (ICARTT), and surface (IMPROVE, EPA-AQS, AERONET) aerosol observations over eastern North America to improve MODIS aerosol retrievals and constrain surface aerosol concentrations and sources, J. Geophys. Res.-Atmos., 115(D14), 2010.

European Environment Agency: Guide to geographical data and maps, January 2006.

Franklin, M., Zeka, A., and Schwartz, J.: Association between PM2.5 and allcause and specific-cause mortality in 27 US communities, J. Expo. Sci. Env. Epid., 17(3), 279-287, 2006.

George, J.J.: Weather forecasting for Aeronautics, Academic Press, New York, 409-415, 1960.

Gotway, C. A. and Young, L. J.: Combining incompatible spatial data, J. Am. Stat. Assoc. 97(458), 632-648, 2002.

Gräler, B., Gerharz, L., and Pebesma, E.: Spatio-temporal analysis and inter750 polation of PM10 measurements in Europe, ETC/ACM Technical Paper 10, 2011.

Gräler, B., Rehr, M., Gerharz, L., and Pebesma, E.: Spatio-temporal analysis and interpolation of PM10 measurements in Europe for 2009, ETC/ACM Technical Paper 8, 2013. 
Greater London Authority: https://www.london.gov.uk, last access: 12 December 2014.

Gupta, P. and Christopher, S. A.: Particulate matter air quality assessment using integrated surface, satellite, and meteorological products: Multiple regression approach, J. Geophys. Res.-Atmos., 114(D14), 2009a.

Gupta, P. and Christopher, S. A.: Particulate matter air quality assessment using integrated surface, satellite, and meteorological products: 2. A neural network approach, J. Geophys. Res.-Atmos., 114(D20), 2009b.

Hansen, B.E.: Sample splitting and threshold estimation, Econometrica, 68(3), 575-603, 2000.

Katsouyanni, K., Touloumi, G., Samoli, E., Gryparis, A., Le Tertre, A., Monopolis, Y., Rossi, G., Zmirou, D., Ballester, F., Boumghar, A., Anderson, H.R., Wojtyniak, B., Paldy, A., Braunstein, R., Pekkanen, J., Schindler, C., and Schwartz, J.: Confounding and effect modification in the short-term effects of ambient particles on total mortality: results from 29 European cities within the APHEA2 project, Epidemiology, 12(5), 521-531, 2001.

Kloog, I., Koutrakis, P., Coull, B. A., Lee, H. J., and Schwartz, J.: Assessing temporally and spatially resolved PM2.5 exposures for epidemiological studies using satellite aerosol optical depth measurements, Atmos. Environ., 45(35), 6267-6275, 2011.

Kloog, I., Nordio, F., Coull, B. A., and Schwartz, J.: Incorporating local land use regression and satellite aerosol optical depth in a hybrid model of spatiotemporal PM2.5 exposures in the Mid-Atlantic states, Environ. Sci. Technol., 46(21), 11913-11921, 2012.

Kokhanovsky, A. A.: Remote sensing of atmospheric aerosol using spaceborne optical observations, Earth-Sci. Rev., 116, 95-108, 2013. 
Lee, H. J., Liu, Y., Coull, B. A., Schwartz, J., and Koutrakis, P.: A novel calibration approach of MODIS AOD data to predict PM 2.5 concentrations, Atmos. Chem. Phys., 11, 7991-8002, 2011.

Lee, H. J., Coull, B. A., Bell, M. L., and Koutrakis, P.: Use of satellite-based aerosol optical depth and spatial clustering to predict ambient PM 2.5 concentrations, Environ. Res., 118, 8-15, 2012.

Levy, R. C., Mattoo, S., Munchak, L. A., Remer, L. A., Sayer, A. M., Patadia, F., and Hsu, N. C.: The Collection 6 MODIS aerosol products over land and ocean, Atmos. Meas. Tech., 6, 2989-3034, 2013.

Lin, C., Li, Y., Yuan, Z., Lau, A. K., Li, C., and Fung, J. C.: Using satellite remote sensing data to estimate the high-resolution distribution of groundlevel PM 2.5, Remote Sens. Environ., 156, 117-128, 2015.

Lindberg, F. and Grimmond, C.S.B.: Continuous sky view factor maps from high resolution urban digital elevation models, Climate Res., 42, 177-183, 2010.

Liu, Y., Sarnat, J. A., Kilaru, V., Jacob, D. J., and Koutrakis, P.: Estimating ground-level PM2.5 in the eastern United States using satellite remote sensing, Environ. Sci. Technol., 39(9), 3269-3278, 2005.

Liu, Y., Franklin, M., Kahn, R., and Koutrakis, P.: Using aerosol optical thickness to predict ground-level PM 2.5 concentrations in the St. Louis area: a comparison between MISR and MODIS, Remote Sens. Environ., 107(1), 3344, 2007.

Liu, Y., Paciorek, C. J., and Koutrakis, P.: Estimating regional spatial and temporal variability of PM2.5 concentrations using satellite data, meteorology, and land use information, Environ. Health Persp., 117, 886-892, 2009.

London Air Quality Monitoring Network: http://www.londonair.org.uk/, last access: 12 December 2014. 
Lyapustin, A., Wang, Y., Laszlo, I., Kahn, R., Korkin, S., Remer, L., Levy, R., and Reid, J. S.: Multiangle implementation of atmospheric correction ${ }_{810}$ (MAIAC): 2. Aerosol algorithm, J. Geophys. Res. - Atmos., 116(D3), 2011.

Nordio, F., Kloog, I., Coull, B. A., Chudnovsky, A., Grillo, P., Bertazzi, P. A., Baccarelli A. A., and Schwartz, J.: Estimating spatio-temporal resolved PM10 aerosol mass concentrations using MODIS satellite data and land use regression over Lombardy, Italy, Atmos. Environ., 74, 227-236, 2013.

North, P., Grey, W., Heckel, A., Fischer, J., Preusker, R. and Brockmann, C.: MERIS/AATSR Synergy Algorithms for Cloud Screening, Aerosol Retrieval, and Atmospheric Correction, in: Algorithm Theoretical Basis Document Land Aerosol and Surface Reflectance ATBD, ESRIN Contract No. 21090/07/I-LG, 2009.

820 Pebesma, E. J.: Multivariable geostatistics in S: the gstat package, Comput. Geosci., 30(7), 683-691, 2004.

Pinheiro, J.C. and Bates, D.M.: Mixed effects models in S and S-plus, Springer, 2006.

Remer, L. A., Kaufman, Y. J., Tanré, D., Mattoo, S., Chu, D. A., Martins, J. V., Li, R-R., Ichoku, C., Levy, R. C., Kleidman, R. G., Eck, T. F., Vermote, E., and Holben, B. N. : The MODIS aerosol algorithm, products, and validation., J. Atmos. Sci., 62(4), 947-973, 2005.

Remer, L. A., Mattoo, S., Levy, R. C., and Munchak, L.: MODIS 3km aerosol product: algorithm and global perspective, Atmos. Meas. Tech., 6, 1829-1844, 2013.

Schaap, M., Apituley, A., Timmermans, R. M. A., Koelemeijer, R. B. A., and de Leeuw, G.: Exploring the relation between aerosol optical depth and PM2.5 at Cabauw, the Netherlands, Atmos. Chem. Phys., 9, 909-925, 2009. 
Song, W., Jia, H., Huang, J., and Zhang, Y.: A satellite-based geographically weighted regression model for regional PM 2.5 estimation over the Pearl River Delta region in China, Remote Sens. Environ., 154, 1-7, 2014.

Urban Atlas: http://land.copernicus.eu/local/urban-atlas, last access: 12 December 2014.

van Donkelaar, A., Martin, R. V., and Park, R. J.: Estimating ground level PM2.5 using aerosol optical depth determined from satellite remote sensing, J. Geophys. Res. - Atmos., 111(D21), 2006.

van de Kassteele, J., Koelemeijer, R. B. A., Dekkers, A. L. M., Schaap, M., Homan, C. D., and Stein, A.: Statistical mapping of PM10 concentrations over Western Europe using secondary information from dispersion modeling and MODIS satellite observations, Stoch. Env. Res. Risk. A., 21(2), 183-194, 2006.

Wang, J. and Christopher, S.A.: Intercomparison between satellite-derived aerosol optical thickness and PM2.5 mass: Implication for air quality studies, Geophys. Res. Lett., 30, 2095, 2003.

Wang, J., Xu, X., Spurr, R., Wang, Y., and Drury, E.: Improved algorithm for MODIS satellite retrievals of aerosol optical thickness over land in dusty atmosphere: Implications for air quality monitoring in China, Remote Sens. Environ., 114, 2575-2583, 2010.

Wu, Y., Guo, J., Zhang, X., Tian, X., Zhang, J., Wang, Y., Duan, J., and Li, X.: Synergy of satellite and ground based observations in estimation of particulate matter in eastern China., Sci. Total Environ., 433, 20-30, 2012.

Young, L. J., Gotway, C. A., Yang, J., Kearney, G., and DuClos, C.: Linking health and environmental data in geographical analysis: It's so much more than centroids, Spatial and spatio-temporal epidemiology 1(1), 73-84, 2009.

Zakšek, K., Oštir, K., and Kokalj, Z̆.: Sky-view factor as a relief visualization technique, Remote Sensing 3(2), 398-415, 2011. 
Zuur, A., Ieno, E. N., Walker, N., Saveliev, A. A., and Smith, G. M.: Mixed effects models and extensions in ecology with R, Springer, 2009. 


\section{List of Figure Captions}

Figure 8: Scatter plots of: (a) AOT versus PM10[kriged]; (b) PM10[estimated] by LMM1 model versus PM10[kriged]; (c) AOT versus PM2.5[kriged]; (d) PM2.5[estimated] by $L M M 1$ model versus PM2.5[kriged] 
${ }_{890}$ Figure 9: Mean concentration $\left[\mu \mathrm{gm}^{-3}\right]$ of (a) PM10 and (b) PM2.5 in each $1 \mathrm{~km} \times 1 \mathrm{~km}$ grid cell estimated by the $L M M 1$ mixed-effects models, for the entire study period (2002-2012). 
Table 1: Mean PM10 concentrations for different land cover class.

S.L. - Sealing Layer

\begin{tabular}{clcc}
\hline$\#$ & LUC class & Estimate $\left[\mu \mathbf{g m}^{-\mathbf{3}}\right]$ & Std.Error $\left[\mu \mathbf{g m}^{-\mathbf{3}}\right]$ \\
\hline 1 & Agricultural - Semi-natural areas - Wetlands & 21.01 & 0.23 \\
2 & Sports and leisure facilities & 22.25 & 0.17 \\
3 & Green urban areas & 23.00 & 0.17 \\
4 & Airports & 26.31 & 0.27 \\
5 & Discontinuous Medium D. Urban Fabric (S.L. : 30\% - 50\%) & 26.88 & 0.05 \\
6 & Discontinuous Dense Urban Fabric (S.L. : 50\% - 80\%) & 26.96 & 0.12 \\
7 & Industrial, commercial, public, military and private units & 27.38 & 0.05 \\
8 & Port areas & 28.09 & 0.58 \\
9 & Other roads and associated land & 28.48 & 0.17 \\
10 & Continuous Urban Fabric (S.L. : 50\% - 80\%) & 29.74 & 0.12 \\
\hline
\end{tabular}

Table 2: p-values for testing the null hypothesis: $\mathbf{H}_{\mathbf{0}}: \mathbf{L} \mathbf{U} \mathbf{C}_{\mathbf{i}}-\mathbf{L U C}_{\mathbf{j}}=\mathbf{0}$ vs $\mathbf{H}_{\mathbf{1}}: \mathbf{L U C}_{\mathbf{i}}-\mathbf{L U C}_{\mathbf{j}} \neq \mathbf{0}$.

\begin{tabular}{|c|c|c|c|c|c|c|c|c|c|}
\hline $\mathbf{j}$ & 1 & 2 & 3 & 4 & 5 & 6 & 7 & 8 & 9 \\
\hline 1 & - & - & - & - & - & - & - & - & - \\
\hline 2 & $<0.001$ & - & - & - & - & - & - & - & - \\
\hline 3 & $<0.001$ & 0.051 & - & - & - & - & - & - & - \\
\hline 4 & $<0.001$ & $<0.001$ & $<0.001$ & - & - & - & - & - & - \\
\hline 5 & $<0.001$ & $<0.001$ & $<0.001$ & 0.358 & - & - & - & - & - \\
\hline 6 & $<0.001$ & $<0.001$ & $<0.001$ & 0.443 & 0.999 & - & - & - & \\
\hline 7 & $<0.001$ & $<0.001$ & $<0.001$ & $<0.01$ & 0.022 & $<0.001$ & - & - & - \\
\hline 8 & $<0.001$ & $<0.001$ & $<0.001$ & 0.107 & 0.597 & 0.474 & 0.957 & - & - \\
\hline 9 & $<0.001$ & $<0.001$ & $<0.001$ & $<0.001$ & $<0.001$ & $<0.001$ & $<0.001$ & 0.999 & - \\
\hline 10 & $<0.001$ & $<0.001$ & $<0.001$ & $<0.001$ & $<0.001$ & $<0.001$ & $<0.001$ & 0.108 & $<0.001$ \\
\hline
\end{tabular}


Table 3: Merged land cover categories.

\begin{tabular}{cl}
\hline Category & Land Cover Class \\
\hline I & Agricultural - Semi-natural areas - Wetlands \\
& Forests \\
& Land without current use \\
& Water bodies \\
\hline II & Sports and leisure facilities \\
& Discontinuous Very Low Density Urban Fabric (S.L. $<10 \%)$ \\
& Discontinuous Low Density Urban Fabric (S.L. : 10\% - 30\%) \\
& Green urban areas \\
\hline III & Airports \\
& Discontinuous Medium Density Urban Fabric (S.L. : 30\% - 50\%) \\
& Discontinuous Dense Urban Fabric (S.L. : 50\% - 80\%) \\
\hline IV & Construction sites \\
& Industrial, commercial, public, military and private units \\
& Isolated Structures \\
& Mineral extraction and dump sites \\
\hline VI & Fast transit roads and associated land \\
& Other roads and associated land \\
& Port areas \\
& Railways and associated land \\
\hline &
\end{tabular}


Table 4: Annual averages of $P M 10$ and $P M 2.5$ concentrations from 2002 to 2012. SE - Standard Error

\begin{tabular}{lcccccc}
\hline Year & \# PM10 stations & Mean $\left[\mu \mathbf{g m}^{-\mathbf{3}}\right]$ & $\mathbf{S E}\left[\mu \mathbf{g m}^{-\mathbf{3}}\right]$ & \# PM2.5 stations & Mean $\left[\mu \mathbf{g m}^{-\mathbf{3}}\right]$ & $\mathbf{S E}\left[\mu \mathbf{g m}^{-\mathbf{3}}\right]$ \\
\hline 2002 & 52 & 28.70 & 0.09 & 4 & 13.59 & 0.18 \\
2003 & 54 & 32.04 & 0.11 & 4 & 16.17 & 0.22 \\
2004 & 67 & 27.45 & 0.09 & 4 & 14.79 & 0.16 \\
2005 & 71 & 28.32 & 0.10 & 7 & 15.39 & 0.18 \\
2006 & 77 & 27.91 & 0.10 & 7 & 16.16 & 0.15 \\
2007 & 72 & 27.41 & 0.10 & 12 & 16.18 & 0.15 \\
2008 & 74 & 25.40 & 0.08 & 15 & 14.96 & 0.12 \\
2009 & 72 & 25.07 & 0.08 & 19 & 14.41 & 0.09 \\
2010 & 70 & 24.91 & 0.07 & 18 & 14.66 & 0.09 \\
2011 & 64 & 26.71 & 0.09 & 20 & 15.62 & 0.12 \\
2012 & 54 & 25.29 & 0.09 & 20 & 14.08 & 0.11 \\
Overall & - & 27.20 & 0.09 & - & 15.09 & 0.14 \\
\hline
\end{tabular}


Table 5: Leave-one-station-out cross validation results of ordinary 2-D kriging using daily variograms $\left(\mathbf{R M S E}\left[\mu \mathbf{g m}^{-3}\right], \mathbf{M E}\left[\mu \mathbf{g m}^{-3}\right], \mathbf{M A E}\left[\mu \mathbf{g m}^{-3}\right]\right.$ and R) applied to raw PM10, log-transformed PM10, residuals of raw PM10 and residuals of log-transformed PM10.

\begin{tabular}{|c|c|c|c|c|c|c|c|c|}
\hline \multirow[b]{2}{*}{ Year } & \multicolumn{4}{|c|}{ raw PM10 } & \multicolumn{4}{|c|}{$\log$ PM10 } \\
\hline & RMSE & ME & MAE & $\mathbf{R}$ & RMSE & ME & MAE & $\mathbf{R}$ \\
\hline 2002 & 8.20 & -0.03 & 5.24 & 0.77 & 8.08 & -0.14 & 5.20 & 0.77 \\
\hline 2003 & 8.58 & -0.03 & 5.85 & 0.85 & 8.46 & -0.13 & 5.79 & 0.85 \\
\hline 2004 & 9.55 & -0.04 & 5.40 & 0.75 & 9.36 & -0.10 & 5.31 & 0.76 \\
\hline 2005 & 10.71 & -0.04 & 6.05 & 0.74 & 10.62 & -0.06 & 6.01 & 0.74 \\
\hline 2006 & 10.84 & -0.04 & 5.91 & 0.73 & 10.78 & 0.03 & 5.82 & 0.73 \\
\hline 2007 & 11.03 & -0.02 & 6.29 & 0.76 & 10.73 & 0.07 & 6.10 & 0.78 \\
\hline 2008 & 9.28 & -0.03 & 5.86 & 0.77 & 9.10 & -0.02 & 5.73 & 0.78 \\
\hline 2009 & 8.96 & -0.02 & 5.55 & 0.70 & 8.69 & -0.13 & 5.48 & 0.72 \\
\hline 2010 & 8.04 & -0.01 & 5.37 & 0.71 & 7.99 & -0.14 & 5.37 & 0.71 \\
\hline 2011 & 7.61 & -0.02 & 5.47 & 0.85 & 7.54 & -0.05 & 5.42 & 0.85 \\
\hline 2012 & 8.00 & -0.07 & 5.50 & 0.82 & 7.87 & -0.11 & 5.44 & 0.83 \\
\hline \multirow[t]{2}{*}{ Mean } & 9.16 & -0.03 & 5.66 & 0.77 & 9.02 & -0.07 & 5.61 & 0.78 \\
\hline & \multicolumn{4}{|c|}{ Residuals raw PM10 } & \multicolumn{4}{|c|}{ Residuals log PM10 } \\
\hline Year & RMSE & ME & MAE & $\mathbf{R}$ & RMSE & ME & MAE & $\mathbf{R}$ \\
\hline 2002 & 7.92 & -0.02 & 5.09 & 0.78 & 7.91 & -0.21 & 5.07 & 0.79 \\
\hline 2003 & 8.17 & -0.02 & 5.49 & 0.86 & 8.05 & -0.14 & 5.35 & 0.87 \\
\hline 2004 & 9.33 & -0.03 & 5.23 & 0.76 & 9.19 & -0.13 & 5.14 & 0.77 \\
\hline 2005 & 10.65 & -0.04 & 5.91 & 0.74 & 10.59 & -0.16 & 5.89 & 0.75 \\
\hline 2006 & 10.80 & -0.04 & 5.79 & 0.73 & 10.78 & -0.06 & 5.73 & 0.73 \\
\hline 2007 & 10.64 & -0.01 & 5.97 & 0.78 & 10.44 & 0.08 & 5.87 & 0.79 \\
\hline 2008 & 8.86 & -0.03 & 5.53 & 0.79 & 8.79 & 0.00 & 5.43 & 0.80 \\
\hline 2009 & 8.69 & -0.02 & 5.34 & 0.72 & 8.44 & -0.13 & 5.27 & 0.74 \\
\hline 2010 & 7.75 & -0.02 & 5.18 & 0.73 & 7.70 & -0.14 & 5.13 & 0.74 \\
\hline 2011 & 7.22 & -0.02 & 5.14 & 0.87 & 7.22 & -0.08 & 5.11 & 0.87 \\
\hline 2012 & 7.69 & -0.05 & 5.22 & 0.83 & 7.55 & -0.14 & 5.10 & 0.84 \\
\hline Mean & 8.88 & -0.03 & 5.44 & 0.78 & 8.79 & -0.10 & 5.37 & 0.79 \\
\hline
\end{tabular}


Table 6: Cross validation results for the interpolation of PM10: 3-D kriging.

\begin{tabular}{ccccccccc}
\hline Year & $\mathbf{n}$ & $\mathbf{p s}$ & $\mathbf{r}[\mathbf{k m}]$ & $\mathbf{S c a l e}[\mathbf{k m} / \mathbf{d a y}]$ & $\mathbf{R M S E}\left[\mu \mathbf{g m}^{-3}\right]$ & $\mathbf{M E}\left[\mu \mathbf{g m}^{-\mathbf{3}}\right]$ & $\mathbf{M A E}\left[\mu \mathbf{g m}^{-\mathbf{3}}\right]$ & $\mathbf{R}$ \\
\hline 2002 & 0.04 & 0.11 & 70 & 18.0 & 8.07 & -0.08 & 5.16 & 0.78 \\
2003 & 0.03 & 0.15 & 90 & 18.0 & 8.34 & -0.09 & 5.59 & 0.86 \\
2004 & 0.05 & 0.14 & 76 & 14.0 & 9.48 & -0.06 & 5.42 & 0.75 \\
2005 & 0.07 & 0.17 & 82 & 13.5 & 10.8 & -0.10 & 6.17 & 0.74 \\
2006 & 0.07 & 0.15 & 84 & 13.0 & 10.90 & -0.02 & 5.93 & 0.73 \\
2007 & 0.07 & 0.15 & 83 & 16.0 & 10.44 & 0.00 & 5.92 & 0.79 \\
2008 & 0.07 & 0.16 & 83 & 14.5 & 8.91 & 0.00 & 5.54 & 0.79 \\
2009 & 0.06 & 0.11 & 60 & 14.0 & 8.57 & 0.04 & 5.33 & 0.73 \\
2010 & 0.07 & 0.10 & 71 & 17.5 & 7.87 & 0.00 & 5.23 & 0.73 \\
2011 & 0.06 & 0.12 & 66 & 11.5 & 7.55 & -0.09 & 5.41 & 0.85 \\
2012 & 0.07 & 0.13 & 65 & 13.5 & 8.08 & -0.12 & 5.52 & 0.82 \\
\hline Mean & - & - & - & - & 9.00 & -0.04 & 5.58 & 0.78 \\
\hline
\end{tabular}

Table 7: Cross validation results for the interpolation of PM2.5: 3-D kriging.

\begin{tabular}{ccccccccc}
\hline Year & $\mathbf{n}$ & $\mathbf{p s}$ & $\mathbf{r}[\mathbf{k m}]$ & Scale $[\mathbf{k m} /$ day $]$ & $\mathbf{R M S E}\left[\mu \mathbf{g m}^{-\mathbf{3}}\right]$ & $\mathbf{M E}\left[\mu \mathbf{g m}^{-\mathbf{3}}\right]$ & $\mathbf{M A E}\left[\mu \mathbf{g m}^{-\mathbf{3}}\right]$ & $\mathbf{R}$ \\
\hline 2002 & 0.02 & 0.15 & 72 & 19.0 & 3.24 & -0.01 & 2.46 & 0.87 \\
2003 & 0.00 & 0.20 & 62 & 16.0 & 3.62 & 0.15 & 2.52 & 0.91 \\
2004 & 0.01 & 0.14 & 50 & 14.5 & 4.61 & -0.19 & 3.49 & 0.75 \\
2005 & 0.01 & 0.17 & 66 & 19.5 & 5.42 & -0.28 & 3.49 & 0.76 \\
2006 & 0.00 & 0.20 & 60 & 15.5 & 4.85 & 0.01 & 2.87 & 0.84 \\
2007 & 0.05 & 0.16 & 71 & 17.5 & 5.37 & -0.06 & 3.66 & 0.84 \\
2008 & 0.07 & 0.17 & 61 & 13.0 & 5.30 & -0.15 & 3.86 & 0.79 \\
2009 & 0.06 & 0.15 & 52 & 11.5 & 5.04 & -0.02 & 3.54 & 0.76 \\
2010 & 0.06 & 0.14 & 52 & 13.0 & 5.16 & 0.00 & 3.82 & 0.77 \\
2011 & 0.06 & 0.17 & 70 & 13.0 & 5.62 & -0.02 & 3.72 & 0.83 \\
2012 & 0.08 & 0.19 & 65 & 13.0 & 5.34 & -0.02 & 3.72 & 0.82 \\
\hline Mean & - & - & - & - & 4.87 & -0.05 & 3.38 & 0.81 \\
\hline
\end{tabular}


Table 8: Predictive performance of three mixed-effects model specifications.

\begin{tabular}{|c|c|c|c|c|c|}
\hline & & \multicolumn{2}{|r|}{ PM10 } & \multicolumn{2}{|r|}{ PM2.5 } \\
\hline & Validation Method & 5-fold & leave-one-out & 5-fold & leave-one-out \\
\hline \multirow{5}{*}{$L M M 1$} & $\mathbf{M E}\left[\mu \mathrm{gm}^{-3}\right]$ & 0.12 & 0.18 & 0.25 & 0.47 \\
\hline & MAE $\left[\mu \mathrm{gm}^{-3}\right]$ & 2.14 & 2.06 & 2.24 & 2.19 \\
\hline & 1- MAPE [\%] & 92.52 & 92.89 & 90.36 & 88.28 \\
\hline & 1- MDAPE [\%] & 94.15 & 93.93 & 87.79 & 89.83 \\
\hline & Out of sample $\mathbf{R}^{2}$ & 0.95 & 0.96 & 0.86 & 0.92 \\
\hline \multirow{5}{*}{$L M M 2 a$} & $\mathbf{M E}\left[\mu \mathrm{gm}^{-3}\right]$ & 1.62 & 1.71 & 1.40 & 1.47 \\
\hline & $\mathbf{M A E}\left[\mu \mathrm{gm}^{-3}\right]$ & 7.62 & 7.72 & 5.23 & 5.34 \\
\hline & 1- MAPE [\%] & 73.28 & 72.99 & 69.88 & 69.78 \\
\hline & 1- MDAPE [\%] & 78.71 & 78.53 & 76.12 & 75.81 \\
\hline & Out of sample $\mathbf{R}^{2}$ & 0.36 & 0.37 & 0.30 & 0.37 \\
\hline \multirow{5}{*}{$L M M 2 b$} & $\mathbf{M E}\left[\mu g m^{-3}\right]$ & 1.56 & 1.64 & 1.32 & 1.47 \\
\hline & MAE $\left[\mu \mathrm{gm}^{-3}\right]$ & 7.49 & 7.59 & 5.21 & 5.31 \\
\hline & 1- MAPE [\%] & 73.75 & 73.43 & 70.04 & 70.08 \\
\hline & 1- MDAPE $[\%]$ & 79.61 & 79.22 & 76.99 & 76.45 \\
\hline & Out of sample $\mathbf{R}^{2}$ & 0.38 & 0.39 & 0.30 & 0.37 \\
\hline
\end{tabular}



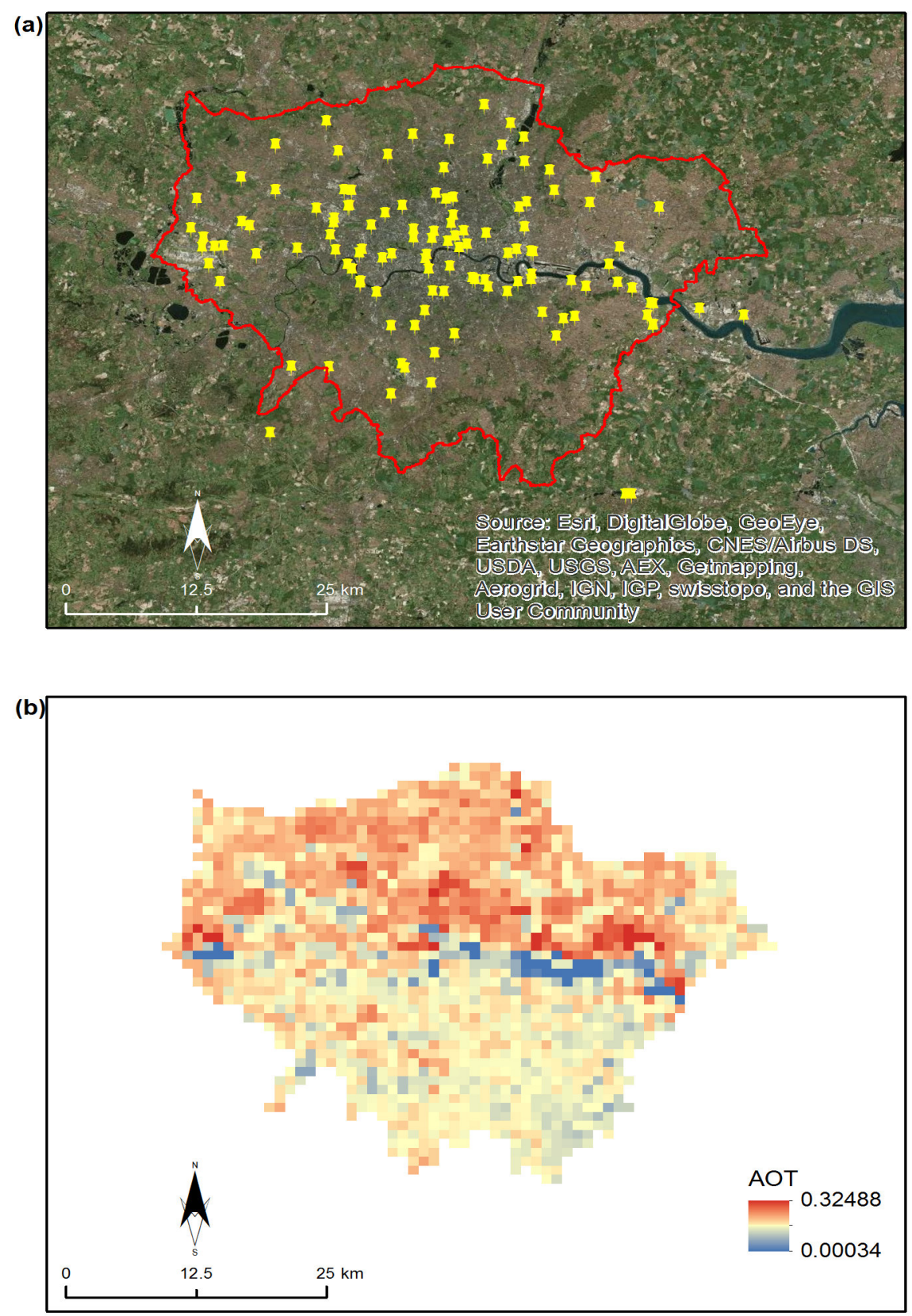

Figure 1: (a) The area of Greater London and the geographical distribution of the London Air Quality Monitoring Network PM10 stations. (b) An example of the final AOT distribution product for August 31, 2005. 

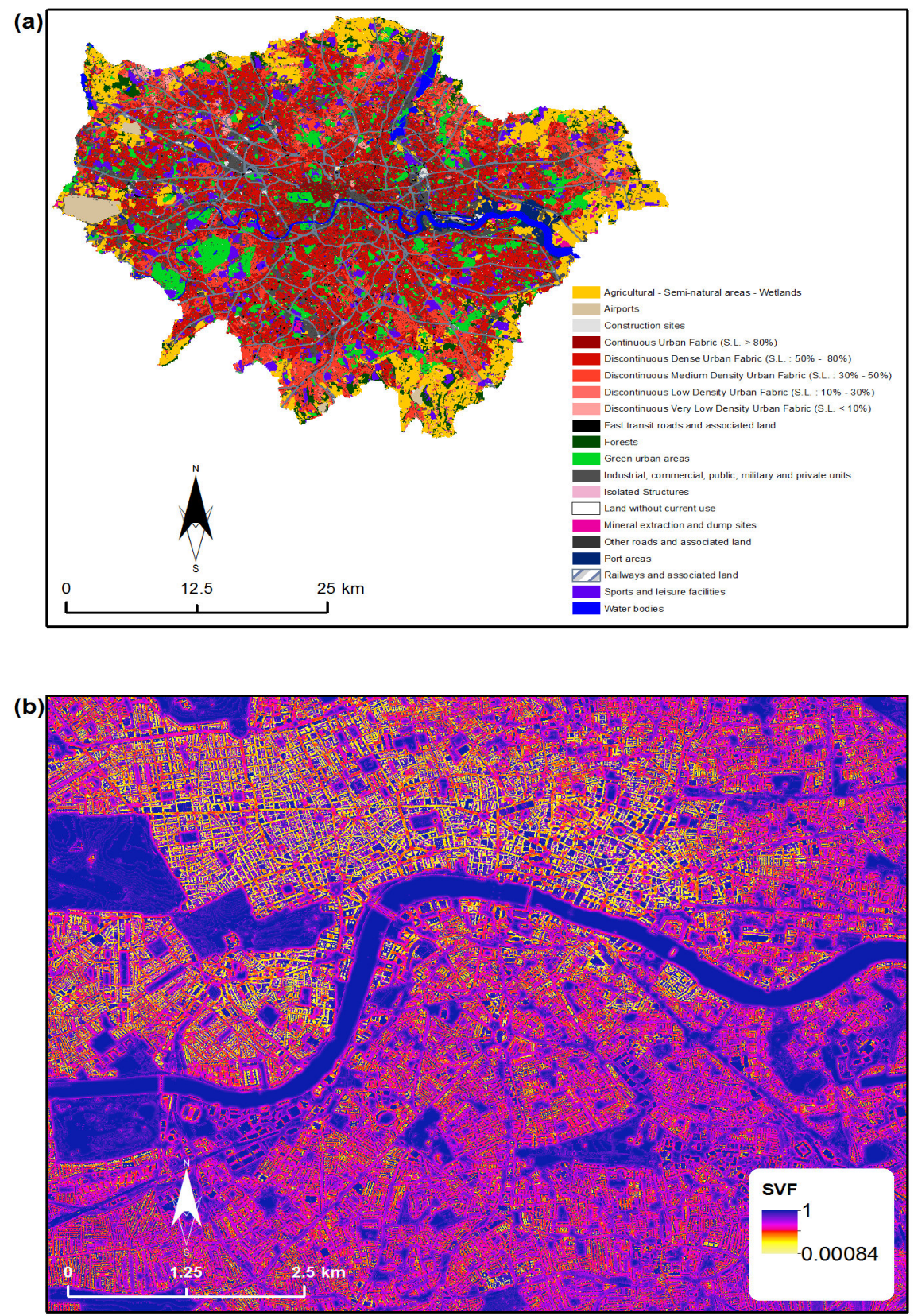

Figure 2: (a) The Urban Atlas LUC map. (b) SVF for the center of London. 


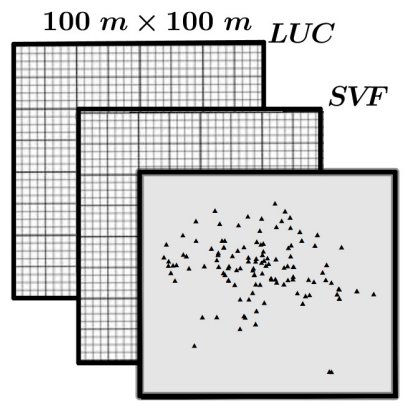

in situ $P M$

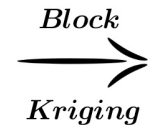

Kriging

Mixed-Effects

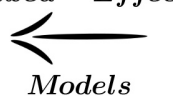

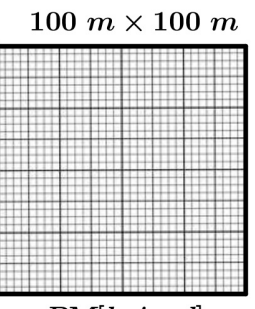

PM [kriged $]$

Upscaling

$1 \mathrm{~km} \times 1 \mathrm{~km}$

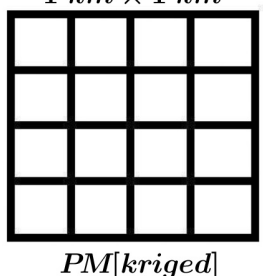

Figure 3: Graphical representation of the developed model: in situ $P M$ data are brought to the spatial scale of the remotely sensed covariates using blockkriging; mixed-effects models are estimated using pixels that contain at least one $P M$ measurement station. 

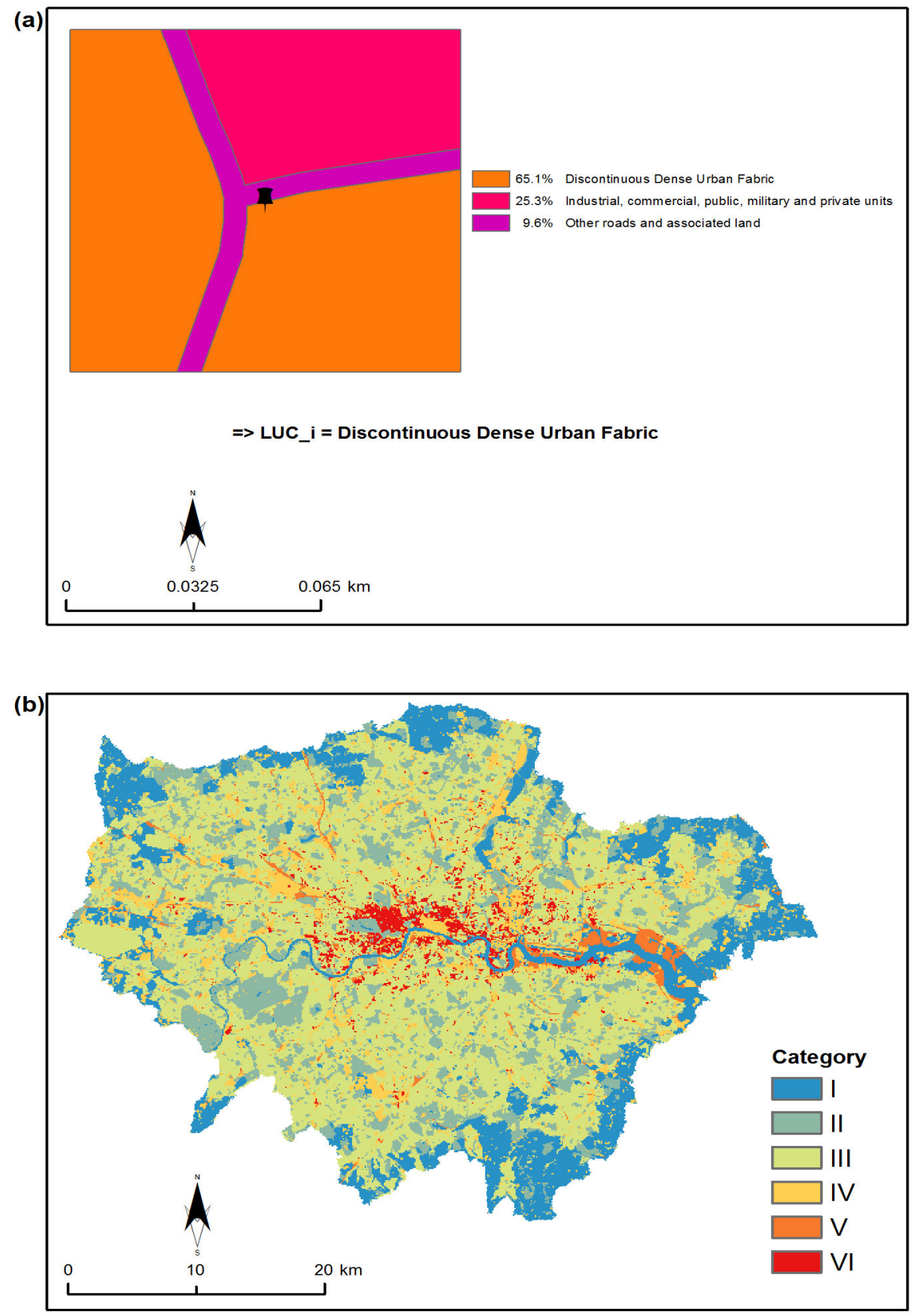

Figure 4: (a) Example of the LUC value assignment to a particular PM location. (b) Merged Raster Map of LUC data at a $100 m \times 100 m$ resolution. 
(a)

Q-Q plot of the residuals (raw PM)

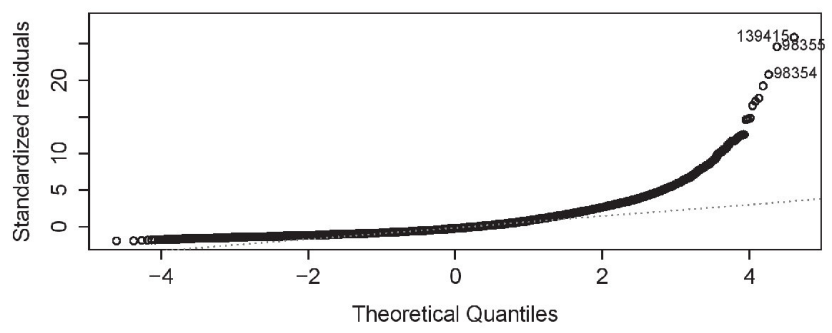

Q-Q plot of the residuals (log-transformed PM)

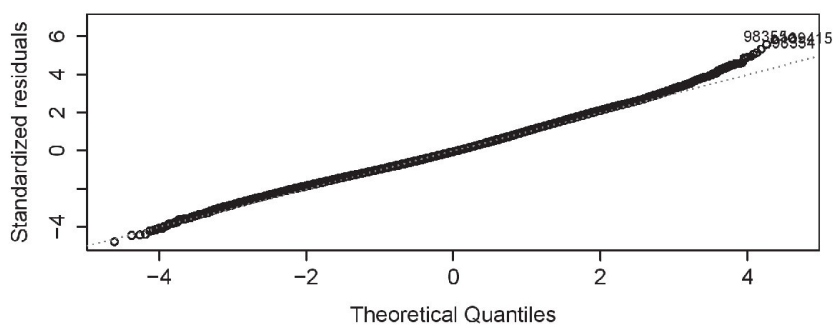

(c)

Histogram of the residuals (log-transformed PM)

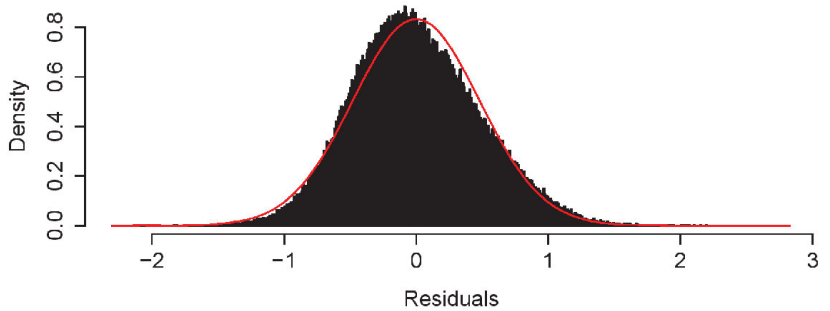

Figure 5: Normal quantile-quantile plot of the regression residuals based on (a) raw $P M$ data and (b) log-transformed data; (c) histogram of the residuals of the second regression model - the red solid curve represents the standard normal distribution. 

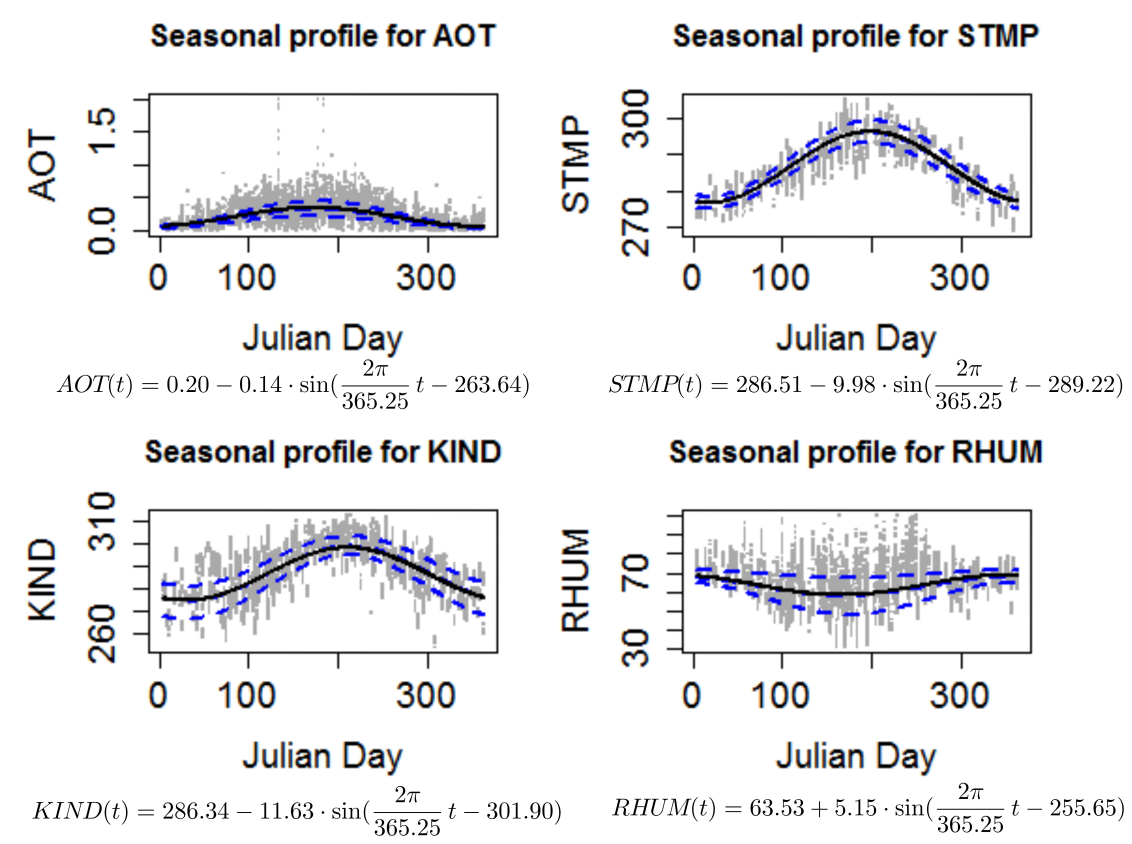

Figure 6: Seasonal profiles of AOT, STMP, KIND and RHUM. Data from the calibration period (11 years) are shown in grey. Solid curves correspond to NLS estimates and middle dashed curves correspond to NAD. Outer dashed curves estimate the 0.25 and 0.75 quantiles of the AOT, STMP, KIND and RHUM, respectively. 
(a)

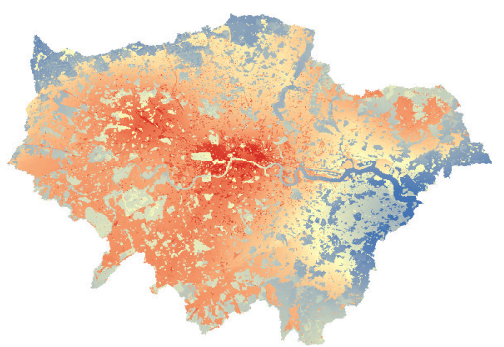

PM10[kriged] $100 \mathrm{~m}$

Mean Concentration 37.48

15.70

(c)

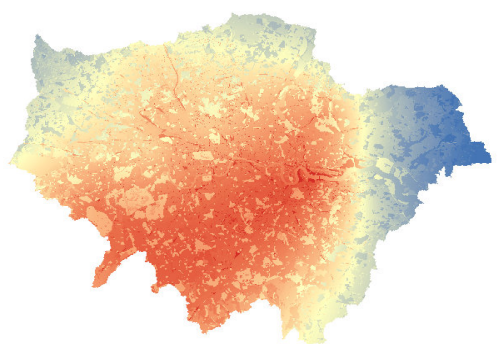

PM2.5[kriged] 100m Mean Concentration 24.16

8.20 (b)

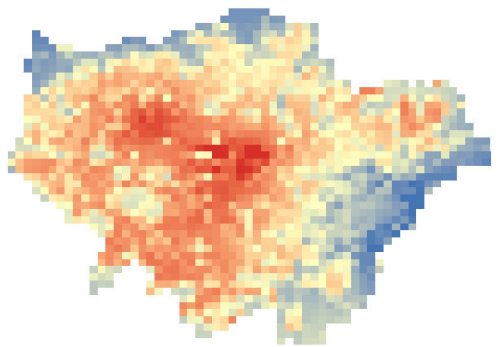

PM10[kriged] $1 \mathrm{~km}$

Mean Concentration

28.17

16.03

(d)



PM2.5[kriged] 1 km

Mean Concentration

19.01

8.56

Figure 7: An example of kriged PM10 $\left[\mathrm{ggm}^{-3}\right]$ surface for September 3, 2011 (a) before and (b) after up-scaling. An example of kriged PM2.5 $\left[\mu \mathrm{gm}^{-3}\right]$ surface for the same day (c) before and (d) after up-scaling. 
(a)

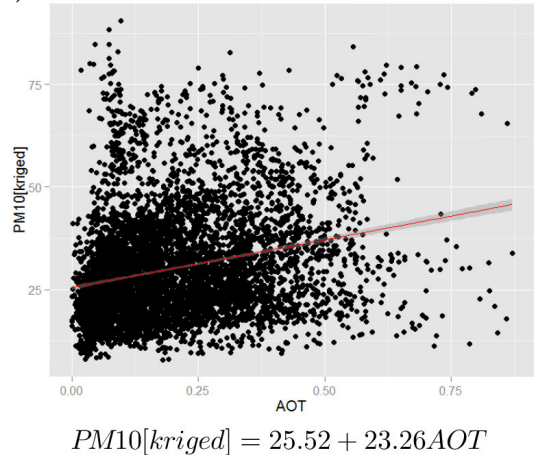

(c)

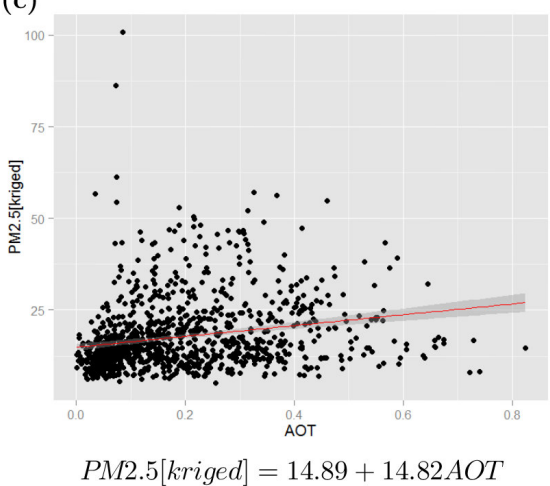

(b)

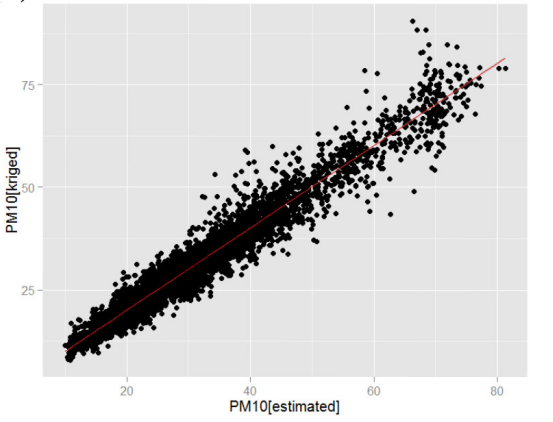

$P M 10[$ kriged $]=0.06+1.00 P M 10[$ estimated $]$

(d)

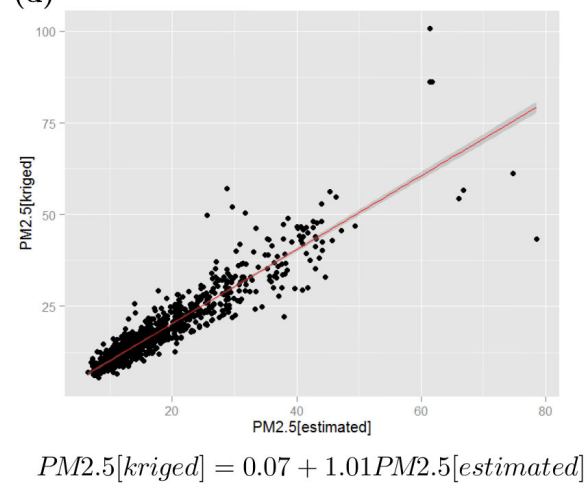

Figure 8: Scatter plots of: (a) AOT versus PM10[kriged]; (b) PM10[estimated] by LMM1 model versus PM10[kriged]; (c) AOT versus PM2.5[kriged]; (d) PM2.5[estimated] by $L M M 1$ model versus PM2.5[kriged] 

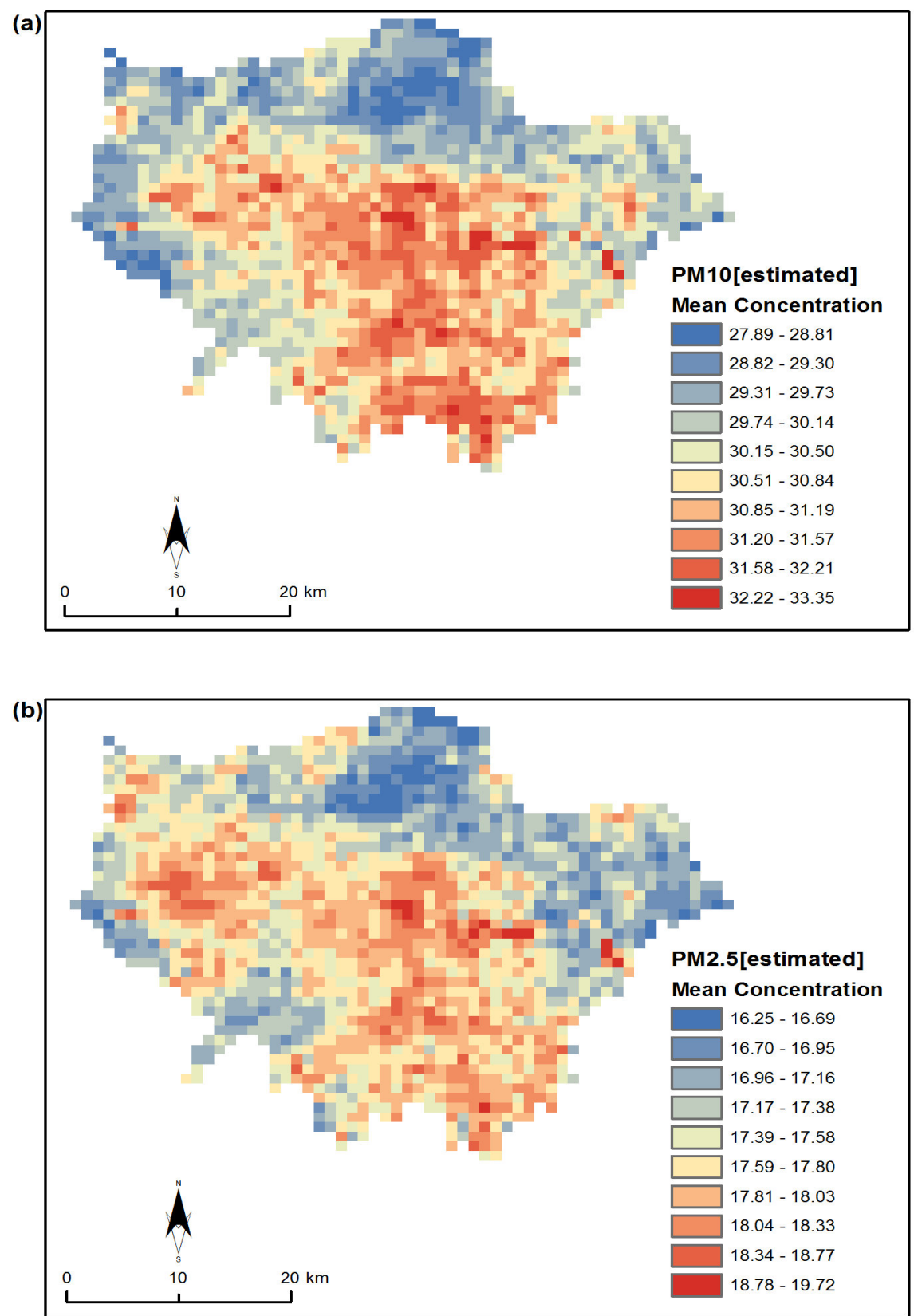

Figure 9: Mean concentration $\left[\mathrm{\mu gm}^{-3}\right]$ of (a) PM10 and (b) PM2.5 in each $1 \mathrm{~km} \times 1 \mathrm{~km}$ grid cell estimated by the $L M M 1$ mixed-effects models, for the entire study period (2002-2012). 